\title{
Effect of the catalyst in fluid bed catalytic hydropyrolysis
}

Stummann, M. Z.; Høj, M.; Davidsen, B.; Hansen, A. B.; Hansen, L. P.; Wiwel, P.; Schandel, C. B.; Gabrielsen, J.; Jensen, P. A.; Jensen, A. D.

\section{Published in:}

Catalysis Today

Link to article, DOI:

10.1016/j.cattod.2019.01.047

Publication date:

2020

Document Version

Peer reviewed version

Link back to DTU Orbit

Citation (APA):

Stummann, M. Z., Høj, M., Davidsen, B., Hansen, A. B., Hansen, L. P., Wiwel, P., Schandel, C. B., Gabrielsen, J., Jensen, P. A., \& Jensen, A. D. (2020). Effect of the catalyst in fluid bed catalytic hydropyrolysis. Catalysis Today, 355, 96-109. https://doi.org/10.1016/j.cattod.2019.01.047

\section{General rights}

Copyright and moral rights for the publications made accessible in the public portal are retained by the authors and/or other copyright owners and it is a condition of accessing publications that users recognise and abide by the legal requirements associated with these rights.

- Users may download and print one copy of any publication from the public portal for the purpose of private study or research.

- You may not further distribute the material or use it for any profit-making activity or commercial gain

- You may freely distribute the URL identifying the publication in the public portal 


\section{Accepted Manuscript}

Title: Effect of the catalyst in fluid bed catalytic hydropyrolysis

Authors: M.Z. Stummann, M. Høj, B. Davidsen, A.B. Hansen, L.P. Hansen, P. Wiwel, C.B. Schandel, J. Gabrielsen, P.A. Jensen, A.D. Jensen

PII: S0920-5861(19)30020-3

DOI: https://doi.org/10.1016/j.cattod.2019.01.047

Reference: CATTOD 11918

To appear in: $\quad$ Catalysis Today

Received date: $\quad 25$ October 2018

Revised date: $\quad 18$ December 2018

Accepted date: $\quad 20$ January 2019

Please cite this article as: Stummann MZ, Høj M, Davidsen B, Hansen AB, Hansen LP, Wiwel P, Schandel CB, Gabrielsen J, Jensen PA, Jensen AD, Effect of the catalyst in fluid bed catalytic hydropyrolysis, Catalysis Today (2019), https://doi.org/10.1016/j.cattod.2019.01.047

This is a PDF file of an unedited manuscript that has been accepted for publication. As a service to our customers we are providing this early version of the manuscript. The manuscript will undergo copyediting, typesetting, and review of the resulting proof before it is published in its final form. Please note that during the production process errors may be discovered which could affect the content, and all legal disclaimers that apply to the journal pertain. 


\section{Effect of the catalyst in fluid bed catalytic hydropyrolysis}

M.Z. Stummann ${ }^{a}$, M. Høja , B. Davidsen ${ }^{b}$, A. B. Hansen ${ }^{b}$, L. P. Hansen ${ }^{b}$, P. Wiwel ${ }^{b}$, C. B. Schandela, J. Gabrielsen $^{b}$, P. A. Jensen ${ }^{a}$, A. D. Jensen ${ }^{a^{*}}$

${ }^{a}$ Department of Chemical and Biochemical Engineering, Technical University of Denmark (DTU), 2800 Kgs.

Lyngby (Denmark)

${ }^{b}$ Haldor Topsøe A/S, 2800 Kgs. Lyngby (Denmark)

$\underline{* a j @ k t . d t u . d k}$

Graphical abstract

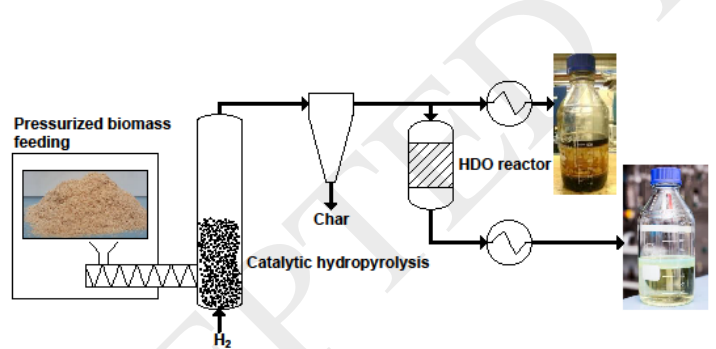

\section{Highlights}

- Using catalysts supports as bed material gave a high char and coke yield

- SEM-EDS showed that the spent supported catalysts had a low carbon content

- A condensable organic yield (oxygen free) of $24.7 \mathrm{wt}$.\% was obtained with bog iron

- Bog iron had a low cracking activity and had low coke deposition

- Bog iron could potentially replace NiMo and CoMo catalysts in this process 


\begin{abstract}
Catalytic hydropyrolysis of beech wood was conducted in a fluid bed reactor followed by a hydrodeoxygenation reactor with a sulfided $\mathrm{NiMo} / \mathrm{Al}_{2} \mathrm{O}_{3}$ catalyst. In order to evaluate the effect of the catalyst in the fluid bed reactor, six different bed materials were tested. Conducting the hydropyrolysis using only the catalyst support materials $\mathrm{MgAl}_{2} \mathrm{O}_{4}$ or zeolite mixed with $\mathrm{Al}_{2} \mathrm{O}_{3}\left(\mathrm{H}-\mathrm{ZSM}-5-\mathrm{Al}_{2} \mathrm{O}_{3}\right)$ gave a high char and coke yield (18.7-21.1 wt.\% dry ash free (daf)), $\mathrm{CO}$ and $\mathrm{CO}_{2}$ (18.9 and 20.0 wt.\% daf), and low yield of condensed organics and $\mathrm{C}_{4+}$ gasses (17.8-20.4 wt.\% daf). Using the supported catalysts $\mathrm{CoMo} / \mathrm{MgAl}_{2} \mathrm{O}_{4}$ or $\mathrm{NiMo} / \mathrm{H}-\mathrm{ZSM}-5-\mathrm{Al}_{2} \mathrm{O}_{3}$ significantly decreased the char yield to between 11.4 and $13.1 \mathrm{wt} . \%$ daf, while the condensed organics and $\mathrm{C}_{4+}$ yield increased to $21.5 \mathrm{wt} . \%$ daf for the $\mathrm{CoMo} / \mathrm{MgAl}_{2} \mathrm{O}_{4}$ and $24.0 \mathrm{wt} . \%$ daf for the $\mathrm{NiMo} / \mathrm{H}-\mathrm{ZSM}-5-\mathrm{Al}_{2} \mathrm{O}_{3}$. As an alternative to the (commercial) supported catalysts, a cheap natural mineral bog iron was tested as catalyst and gave a condensed organics and $\mathrm{C}_{4+}$ yield of $22.8 \mathrm{wt} . \%$ daf when pre-sulfiding the bog iron, while the yield was $24.7 \mathrm{wt.} \%$ daf when the bog iron was used un-sulfided, but reduced prior to the experiment. This indicates that bog iron is the most suitable catalyst in the fluid bed reactor.
\end{abstract}

\author{
Abbreviations \\ AED Atomic emission detector \\ BET Brunauer-Emmett-Teller \\ Bl Bog iron \\ CoMo $\quad \mathrm{CoMo} / \mathrm{MgAl}_{2} \mathrm{O}_{4}$ \\ conc Concentration \\ daf Dry, ash free basis \\ $\mathrm{db} \quad$ Dry basis
}


diAro Diaromatics

DMDS Dimethyl disulfide

EDS Energy dispersive X-ray emission spectroscopy

FB Fluid bed

FID Flame ionization detector

GC Gas chromatograph

HAADF High-angle annular dark-field

HDO Hydrodeoxygenation

ICP-OES Inductive coupled plasma optical emission spectroscopy

mAro Monoaromatics

$\mathrm{MgAl} \quad \mathrm{MgAl}_{2} \mathrm{O}_{4}$

MS Mass spectrometry

Naph Naphthenes

NiMoZA NiMo/H-ZSM-5 mixed with $\mathrm{Al}_{2} \mathrm{O}_{3}$

O-Ali Oxygenated aliphatics

O-Aro Larger oxygenated aromatics

OS Olivine sand

Par Paraffins

$\mathrm{PhOH} \quad$ Oxygenated aromatics (phenols)

$\mathrm{Ph}(\mathrm{OH}) 2$ Dihydroxybenzene

SEM Scanning electron microscopy

SIMDIS Simulated distillation by GC

STEM Scanning transmission electron microscopy

Temp. Temperature

tetAro+ Tetra- and higher aromatics 
triAro Triaromatics

\section{Introduction}

The worlds energy consumption continues to increase, with transport being one of the major energy consumers [1,2]. The transportation sector is responsible for more than one fourth of the energy consumption in the United States [1], where liquid transportation fuels are mainly produced from crude oil. However, the reserves of fossil oil are depleting [3] and their use contributes to global warming through emission of carbon dioxide [4]. Therefore, it is necessary to find carbon neutral alternative fuels. Lignocellulosic biomass can be converted into a liquid bio-oil by fast pyrolysis, where the biomass is rapidly heated to approximately $500{ }^{\circ} \mathrm{C}$ in an inert atmosphere [5]. The produced bio-oil has a high oxygen and water content [5-8], thus its heating value is less than half that of conventional liquid fuel $[8,9]$. Due to the high oxygen content the bio-oil is immiscible with conventional petroleum oils, it is acidic and has a tendency to polymerize during storage $[5,10,11]$. Before bio-oil can replace the fossil fuels used in the transportation sector upgrading is necessary [12]. This could be achieved by catalytic hydrodeoxygenation (HDO) where bio-oil oxygenates are hydrogenated to hydrocarbons with water as byproduct. Unfortunately, however, the reactive nature of the bio-oil leads to rapid deactivation of the HDO catalyst by coking [13]. Furthermore, studies have shown that some of the larger, and more problematic molecules, such as anhydro-oligosaccharides, in the bio-oil are formed by polymerization of the pyrolysis vapors in the short time between pyrolysis and condensation of the bio-oil [14]. Catalytic pyrolysis, where the pyrolysis takes place in the presence of a zeolite catalyst in an inert atmosphere, has been used to produce a bio-oil 
with lower oxygen content. However, the carbon recovery for this process is only between 10 and 20 wt.\% and the oxygen content is still significant [15].

Catalytic hydropyrolysis has gained an increasing interest since Marker et al. $[16,17]$ showed that it is possible to obtain an oxygen free oil with a condensed oil and $\mathrm{C}_{4+}$ yield of up to $28 \mathrm{wt} . \%$ daf from maple wood in their process called Integrated Hydropyrolysis and Hydroconversion ( $\left.\mathrm{IH}^{2 \circledast}\right)$. In this process biomass is fed under pressure into a fluid bed reactor, where the catalytic hydropyrolysis takes place, followed by a fixed bed reactor with a hydrotreating catalyst $[16,17]$. The composition of the catalyst in the fluid bed and HDO reactor used in the studies by Marker et al. $[16,17]$ has not been reported. Conducting the hydrodeoxygenation of the reactive oxygenates in the hydropyrolysis reactors, decreases the degree of polymerization, but does not remove all the oxygen in the oil, which is removed in the second reactor. Thermodynamic analysis of energy systems based on catalytic hydropyrolysis followed by a HDO reactor has indicated that it is possible to obtain an energy efficiency of $89 \%$ (LHV) if synthetic natural gas (SNG) is co-produced [19], showing that this is a promising process.

Dayton et al. [18] tested catalytic hydropyrolysis of woody residue with a commercially available hydrotreating catalyst. This gave an initial low oil yield ( $<5 \mathrm{wt} . \%)$, which increased over time to $12.5 \mathrm{wt} . \%$, as the catalyst deactivated. Replacing the catalyst with SiC increased the bio-oil yield to 26.6-42.5 wt. \% with an oxygen content of 34.6-38.8 wt.\% db depending on the operating conditions and thus not much oxygen was removed from the oil [18]. Dayton et al. [20] also investigated the effect of temperature and pressure with a commercially available NiMo hydrotreating catalyst. The used catalyst was prior to the experiment reduced in hydrogen rather than the normal activation by sulfidation to the NiMoS form. Liquid organic yields between 12.6 and 25.6 wt.\% was obtained with an oxygen content between 2.4 and 11.9 wt.\%. The carbon recovery was between 34.8 and $42.0 \%$, which is significantly higher than for catalytic pyrolysis with zeolites. Wang et al. [21] tested 5 different catalysts in a fluid bed reactor at atmospheric hydrogen pressure and was able to obtain an oil and $\mathrm{C}_{4+}$ yield corresponding to a carbon recovery of $43.2 \%$, 
with an oxygen content in the oil of $6.2 \mathrm{wt} . \%$. Other groups have been pursuing high pressure non-catalytic hydropyrolysis in an inverted cyclone or fluid bed reactor followed by a second hydrotreating reactor prior to the oil and water condensation [22-24]. In this concept the deoxygenation only takes place in the HDO reactor, in contrast to the $\mathrm{IH}^{2 \circ}$ process where most of the deoxygenation takes place in the catalytic hydropyrolysis reactor [16]. The role of the catalyst in each of these reactors thus varies depending on the bed material in the catalytic hydropyrolysis reactor.

Catalytic hydropyrolysis has also been studied by several groups using Pyroprobe instruments. Melligan et al. $[25,26]$ have shown that pyrolysis in a $\mathrm{H}_{2}$ atmosphere at elevated pressure with a Ni-ZSM-5 catalyst significantly decreases the concentration of ethanoic acids in the bio-oil compared to performing the pyrolysis in He. Gamliel et al. [27-29] investigated the difference between Ni supported on $\mathrm{SiO}_{2}, \mathrm{Al}_{2} \mathrm{O}_{3}$ and ZSM-5 and found that ZSM-5 gave the lowest solid yield, thus the lowest solid yield was obtained with the catalyst with the highest acidity. They ascribed this to an increase in the acid-catalyzed decarbonylation and aromatization of anhydrosugars and furans to stable products prior to secondary polycondensation reactions [27]. Catalytic hydropyrolysis is to some extent similar to the Bergius process, where coal and heavy oil are mixed into a slurry [30-32] with the purpose of transforming coal to a liquid fuel. However, the Bergius process is a liquid phase reaction, while catalytic hydropyrolysis is a gas phase reaction. Iron sulfide is, due to its moderate price and activity, the most conventional catalyst used in the Bergius process [33] and pyrrhotite $\left(\mathrm{Fe}_{1-x} \mathrm{~S}\right)$ is assumed to be active phase $[34,35]$. The size of the catalyst particles has a significant influence on the catalyst activity and smaller particles are preferred [33,34]. Furthermore, it has been observed that the oil yield increases with decreasing crystallite size of pyrrhotite [36]. Rocha et al. [37] showed using a pyroprobe that conducting hydropyrolysis of cellulose at $10 \mathrm{MPa}$ with a colloid FeS catalyst decreased the oxygen content in the produced bio-oil from $19.9 \%$ to $11.5 \%$.

Despite the recent progress, the knowledge base on catalytic hydropyrolysis is still scarce. Often the catalyst composition is not reported and in most cases when it is reported the experiments are conducted 
in Pyroprobe instruments and not in continuous fluid bed reactors closer to industrial application. In addition, the catalyst used in the catalytic hydropyrolysis reactor is often reduced prior to the experiment, but will most likely over time be partly sulfided due to sulfur in the biomass [6]. Furthermore, the catalysts are often fairly expensive and toxic, containing elements such as $\mathrm{Ni}, \mathrm{Mo}$ and $\mathrm{Co}$. The latter could be a problem because the catalyst is crushed over time and is mixed with the produced char, which might increase the cost for handling this.

In our previous study [38], catalytic hydropyrolysis of beech wood was conducted in a fluid bed reactor with a sulfided commercial CoMo/MgAl ${ }_{2} \mathrm{O}_{4}$ catalyst followed by a $\mathrm{HDO}$ reactor loaded with a sulfided commercial $\mathrm{NiMo} / \mathrm{MgAl}_{2} \mathrm{O}_{4}$ catalyst. The produced organic phase was essentially oxygen free and consisted of naphtha and diesel range hydrocarbons. The fluid bed temperature and pressure were varied, which showed that the interconversion of aromatics into naphthenes was kinetically controlled at temperatures below $430{ }^{\circ} \mathrm{C}$ and equilibrium controlled (limited) at higher temperatures [38]. In this study the effect of the highly important catalyst in the fluid bed reactor is investigated in order to optimize the oil yield, to study the influence on the products and to better understand the interplay between the two catalytic reactors. Commercial catalysts, support materials, and natural minerals were tested in the fluid bed reactor, with aim of exploring the possibility to replace the fairly expensive and toxic CoMo and NiMo catalysts with a cheap and non-toxic alternative. The produced liquid products were analyzed and the spent catalysts were characterized with scanning transmission electron microscopy (STEM), scanning electron microscopy (SEM) combined with energy-dispersive X-ray spectroscopy (EDS), and X-ray diffraction (XRD).

\section{Material and methods}

\subsection{Biomass feedstock}

Bark free beech wood supplied by Dansk Træmel (Product number: 10000251250390) was used as biomass. The wood particles size was approximately $200-700 \mu \mathrm{m}$. The ash content was $0.59 \mathrm{wt}$. $\%$ on dry 
basis $(\mathrm{db})$ and the moisture content was $6.72 \mathrm{wt}$. \% (weight loss by drying at $105^{\circ} \mathrm{C}$ ). The biomass consisted of 49.9 wt.\% db carbon, 6.0 wt.\% db hydrogen, 1.3 wt.\% db nitrogen, 43.0 wt.\% db oxygen, 48 wt-ppm db S, and a more detailed elemental composition can be found elsewhere [38]. The biomass was analyzed by Celignis Analytical (analysis P10) and consisted of 24 wt.\% db lignin, 40 wt.\% db cellulose, 18 wt.\% db hemicellulose, 3 wt.\% db extractives and $12 \mathrm{wt} . \% \mathrm{db}$ unknown.

\subsection{Catalysts}

Six different catalysts were tested in the fluid bed: $\mathrm{A}$ CoMo/MgAl $\mathrm{O}_{4}$ (CoMo), a spinel carrier $\mathrm{MgAl}_{2} \mathrm{O}_{4}$ (MgAl), Olivine sand (OS), bog iron (BI), zeolite (H-ZSM-5) mixed with alumina (ZA), and NiMo on zeolite mixed with alumina (NiMoZA). Bog iron was tested both as a sulfide catalyst (BI-S) and as a reduced catalyst (BI-R). The CoMo and NiMoZA were tested as sulfide catalysts. MgAl was prior to the experiments calcined in air at $960^{\circ} \mathrm{C}$ for 4 hours. The OS (F grade) was supplied by LKAB minerals and more information can be found in the supplementary information Tables S.1 and S.2. The other catalysts (CoMo, NiMo, MgAl, ZA, NiMo, and $\mathrm{BI}$ ) were supplied by Haldor Topsøe A/S. The composition of bog iron is shown in supplementary information Table S.3. In order to obtain a good fluidization of the bed, the particles were crushed to different particle sizes due to the difference in particle density (see Table 1 ). In order to use the same volume of bed material in the experiments, the mass of catalyst in the fluid bed was varied. Therefore, when using CoMo, NiMo, MgAl, and ZA approximately $50 \mathrm{~g}$ were used in the fluid bed, however approximately 140 and $95 \mathrm{~g}$ were loaded when OS and BI were tested, respectively. BI-R and OS were reduced by heating them in situ in $95 \% \mathrm{H}_{2}$ and $5 \% \mathrm{~N}_{2}$ to $400-440{ }^{\circ} \mathrm{C}$ with a heating rate of $10{ }^{\circ} \mathrm{C} / \mathrm{min}$ for $1 \mathrm{~h}$ prior to the experiment, which should be sufficient to reduce the catalyst [39]. The HDO reactor was loaded

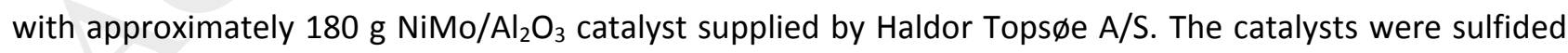
by heating from $\sim 180^{\circ} \mathrm{C}$ to $350^{\circ} \mathrm{C}$ in $1.8-5$ mole $\% \mathrm{H}_{2} \mathrm{~S}$ with a ramp of $10^{\circ} \mathrm{C} / \mathrm{min}$ and hold time of 2 hours at $350^{\circ} \mathrm{C}$. It was assumed that the sulfidation does not affect H-ZSM-5 and therefore this catalyst was not sulfided prior to the experiment, but heated from 300 to $450{ }^{\circ} \mathrm{C}$ in $471 \mathrm{ppm} \mathrm{H}_{2} \mathrm{~S}$. 


\subsection{Experimental setup}

The catalytic hydropyrolysis experiments were conducted in a bench scale setup as shown in Figure 1 . The unit was previously used to conduct a parametric study with a CoMo/ $\mathrm{MgAl}_{2} \mathrm{O}_{4}$ catalyst in the fluid bed and a NiMo/ $/ \mathrm{Al}_{2} \mathrm{O}_{3}$ in the $\mathrm{HDO}$ reactor [38]. The feeding system consisted of a gas mixing system where the gas flows were controlled by Brooks mass flow controllers. A liquid feeding system was used to supply the setup with dimethyl disulfide (DMDS) with a pump and an evaporator (operating at $200{ }^{\circ} \mathrm{C}$ ) for the sulfidation of the catalysts in experiment 1, 2, 3 and 4. DMDS was used instead of $\mathrm{H}_{2} \mathrm{~S}$ during the sulfidation because of the high price of bottled $\mathrm{H}_{2} \mathrm{~S}$. However, using DMDS lead to coking of the gas preheater, and thus bottled $\mathrm{H}_{2} \mathrm{~S}$ was used during the sulfidation in the remaining experiments. The biomass was loaded into a pressurized vessel (volume: $4 \mathrm{~L}$ ) with a feed screw placed at the bottom, which was used to transport the biomass to the feeding tube, where it was rapidly transported by a flow of hydrogen to the reactor. Before entering the fluid bed reactor, the biomass was preheated by heating the feeding tube to approximately $200^{\circ} \mathrm{C}$. The reactor system consisted of a fluid bed hydropyrolysis reactor, a filter and a fixed bed hydrodeoxygenation (HDO) reactor. In order to avoid condensation between the reactors and filter the tubes were heated to approximately $350^{\circ} \mathrm{C}$. The liquid product was collected in a cooling section with three stages $\left(20^{\circ} \mathrm{C}, 2^{\circ} \mathrm{C}\right.$, and $\left.-40^{\circ} \mathrm{C}\right)$. The pressure was controlled with a backpressure regulator and the gas was sent to a flare. A small fraction of the gas was sent to an online gas chromatograph (GC) with a flame ionization detector (FID) and two thermal conductivity detectors (TCD), which measured the gas composition $\left(\mathrm{H}_{2}, \mathrm{H}_{2} \mathrm{~S}, \mathrm{~N}_{2}, \mathrm{CO}, \mathrm{CO}_{2}, \mathrm{C}_{1}\right.$ to $\mathrm{C}_{5}$, and $\mathrm{C}_{6+}$ hydrocarbons) every $10 \mathrm{~min}$. The total mass of the condensed liquid was determined and the organic phase and the aqueous phase were separated with a separation funnel. The mass of the aqueous phase was measured and the mass of the organic phase was determined by subtracting the mass of the aqueous phase from the total mass of condensed liquid. The $\mathrm{H}_{2} \mathrm{~S}$ dissolved in the liquid phases was for safety reasons removed by bubbling with $\mathrm{N}_{2}$ for approximately $0.5-1 \mathrm{~h}$ for the organic phase and 1-2 hours for the aqueous phase. This lead to a mass loss between 2.5 and 6.5 wt.\% for the organic phase and between 0.4 and $3.8 \mathrm{wt} . \%$ in the aqueous phase. The mass loss in the 
organic phase was mainly due to vaporization of light hydrocarbons while the mass loss in the aqueous phase was mainly due to vaporization of water.

It should be noted that the hydrogen flow rate was varied in order to ensure that the gas velocity corresponded to 3 times the minimal fluidization velocity of the bed material to ensure that the bed is wellfluidized. However, since a high surplus of hydrogen was used in all the conducted experiments, it can be assumed that the hydrogen flow does not have an impact on the product distribution and composition. The biomass feeding rate varied between 174 and $302 \mathrm{~g} / \mathrm{h}$, but previous experiments have shown that it does not have an impact on the products [38].

After each experiment the catalyst and remaining char was removed from the fluid bed and filter, and replaced with a fresh batch in the subsequent experiment. The total char and coke yield was calculated by subtracting the amount of loaded catalyst from the total mass of solids collected from the filter and fluid bed.

The catalyst in the HDO reactor was changed after experiment 1, 3, 4 and 5 . The same batch of catalyst was used in the HDO reactor in experiment 4, 7, 9, 10 and 11 and several unpublished experiments have also been conducted with this batch of catalyst in the HDO reactor. After experiment 11 approximately $9750 \mathrm{~g}$ of biomass had been used in experiments with the same catalyst batch in the HDO reactor.

\subsection{Analysis methods}

\subsubsection{Liquid products}

\subsubsection{Organic phase}

Several different methods were used to analyze the condensed organic phase and a more detailed description can be found elsewhere [38]. The hydrogen content was measured with ASTM method D7171. The sulfur content was measured according to ASTM D4294. The simulated distillation (SIMDIS) curves were measured with ASTM method D $7213 \mathrm{C}$. The density at $40{ }^{\circ} \mathrm{C}$ was measured with ASTM method D 
4052, the viscosity at $40{ }^{\circ} \mathrm{C}$ was measured with ASTM method D 7042 and the water content was measured with Karl Fisher titration.

The condensed organic liquid samples were characterized by GCXGC-ToF/MS or -FID using a LECO ${ }^{\circledR}$ Pegasus $4 \mathrm{D}^{\mathrm{TM}}$ instrument. The instrument included an Agilent 7890A GC equipped with a Gerstel ${ }^{\circledR} \mathrm{CIS} 4 \mathrm{PTV}$ inlet, a secondary oven, a quad-jet, dual-stage cryogenic-based (liquid $\mathrm{N}_{2}$ ) modulator, a time-of-flight (ToF) mass spectrometer (MS) and a flame ionization detector (FID). The primary (1D) and secondary (2D) columns were Restek $^{\circledR}$ Rxi-5Sil MS and Restek ${ }^{\circledR}$ Rxi-17Sil MS, respectively. Based on the GCxGC-ToF/MS analysis the compounds were classified into eleven groups: paraffins, naphthenes, mono-, di- and tri- and higher aromatics, oxygenated aliphatics, phenolics, dihydroxybenzenes, larger oxygenated aromatics, and sterols. Based on the retention times of the $n$-paraffins on the 1D column the component classes were split into subgroups on the basis of the number of carbon atoms in the components, i.e. $-\mathrm{C} 10, \mathrm{C} 11-\mathrm{C} 15, \mathrm{C} 16-\mathrm{C} 20$, C20+. However it should be noted that other components classes do not necessarily have the same carbon number distribution as the paraffins, and caution is needed when correlating the relative amount of each subgroup with its carbon number distribution. The relative amount (FID area-\%) of each compound class was estimated as the sum of areas of all detected peaks in that class divided by the total peak area of all compound classes. All data were processed using the ChromaTof ${ }^{\circledast} 4.50$ software.

Selective analysis of oxygenates was conducted using a GC with an atomic emission detector (AED). An Agilent 7890A GC was coupled to a JAS 2370 AED in oxygen selective mode. Quantification was done by adding known amounts of 4-fluorophenol to known amounts of the sample.

For condensed organics phases with a high oxygen content (>2 wt.\%) the carbon or oxygen content was measured by DB Lab A/S using a Flash 2000 elemental analyzer. The uncertainty for this measurement was $3.0 \%$ and $1.0 \%$ for the oxygen and carbon analysis, respectively, defined as two standard deviations for the measurement uncertainty, corresponding to a confidence interval of $95 \%$. The carbon and oxygen 
content in each sample was measured twice and the reported oxygen content is the average of the two measurements.

\subsubsection{Aqueous phase}

The carbon content in the aqueous phase was determined with GC-AED. The samples were analyzed using an Agilent 7890A GC coupled to a JAS 2370 Atomic Emission Detector (AED) in carbon selective mode. The carbon emission line at $193 \mathrm{~nm}$ was used combined with a makeup helium gas flow of $80 \mathrm{ml} / \mathrm{min}$. The cavity was set at $320^{\circ} \mathrm{C}$ and transfer line temperature was set at $380^{\circ} \mathrm{C}$. The $\mathrm{GC}$ column used was a Phenomenex ZB-5 Inferno $(30 \mathrm{~m} \times 0.25 \mathrm{~mm} \times 0.25 \mu \mathrm{m})$ in connection with a JAS PTV inlet in split mode (1:100) held at $325^{\circ} \mathrm{C}$ and $0.5 \mu \mathrm{l}$ injection. The oven was held at $40^{\circ} \mathrm{C}$ for $1 \mathrm{~min}$ and then ramped to $380^{\circ} \mathrm{C} @$ $10^{\circ} \mathrm{C} / \mathrm{min}$. The quantification was done by external calibration using benzyl alcohol dissolved in water as standard. Calibration concentrations ranged from $10 \mathrm{ppm}$ to $1100 \mathrm{ppm}$ carbon. The external standard was used for calibration of unknown carbon containing compounds in the sample as the AED has equimolar and linear response for carbon. No identification of individual compounds was done and the total added amount of detected carbon was taken as a figure of the total carbon content in the water sample. The samples were analyzed as received and no sample pretreatment was done prior to analysis.

The aqueous phase was also analyzed on a Shimadzu GC-MS/FID with a Supelco Equity-5 column. The compounds were identified on the MS and quantified using the parallel FID. Based on the GC-MS/FID analysis the components were classified into 8 groups: unidentified, ethers, ketones, alcohols, sugars, phenols, acids and furans. The relative amount (FID area-\%) of each component class was estimated as the sum of all the detected peaks in that class divided by the total peak area.

\subsubsection{Catalyst characterization}

The composition ( $\mathrm{Al}, \mathrm{Ca}, \mathrm{Cr}, \mathrm{Fe}, \mathrm{Mg}, \mathrm{Mn}, \mathrm{Ni}, \mathrm{Si}, \mathrm{As}, \mathrm{P}$ ) of the fresh $\mathrm{OS}$ and $\mathrm{BI}$ was determined with inductive coupled plasma optical emission spectroscopy (ICP-OES) and the surface area was measured with $\mathrm{N}_{2^{-}}$ physisorption (BET). Fresh $\mathrm{BI}$ and spent $\mathrm{BI}-\mathrm{S}$ and $\mathrm{BI}-\mathrm{R}$ were also analyzed by XRD using a Panalytical XPert Pro instrument system in Bragg-Brentano geometry working in reflectance mode using $\mathrm{Cu} \mathrm{K}_{\alpha}$ radiation $(\lambda=$ 
$1.541 \AA$ A). Rietveld analysis was performed using the Topas Software and reference structures for $\mathrm{FeCO}_{3}$ (ICSD 100678), $\alpha-\mathrm{FeO}(\mathrm{OH})$ (ICSD 77327), $\mathrm{SiO}_{2}$ (ICSD 16331), FeS (ICSD 156618), $\mathrm{Fe}_{0.88} \mathrm{~S}$ (ICSD 151767), $\mathrm{FeS}_{2}$ (ICSD 316), $\mathrm{Fe}$ (ICSD (180969), $\mathrm{CaCO}_{3}$ (ICSD 18166), $\mathrm{Fe}_{3} \mathrm{O}_{4}$ (ICSD 26410), $\mathrm{Fe}_{2} \mathrm{O}_{3}$ (ICSD 15840), and $\mathrm{MgCO}_{3}$ (ICSD 10264). The symmetry and atomic position were fixed and the lattice parameters and average crystal size were refined.

The scanning electron microscopy (SEM) was performed on a FEI QUANTA600 scanning electron microscope with tungsten filament and equipped with a liquid nitrogen cooled EDAX EDS detector. All samples were sprinkled on carbon tabs on Al-stubs and conducted without any coating to prevent charging in the sample chamber. EDS element quantifications were acquired on $0.11 \mathrm{~mm} \times 0.11 \mathrm{~mm}$ areas on the surface of the catalyst grains at $3 \mathrm{kV}, 5 \mathrm{kV}, 10 \mathrm{kV}$ and $15 \mathrm{kV}$ to probe different interaction volumes between the incident electron beam and the sample. The composition of the sample was determined in EDAX software (version 5.2.42) using a normalized, standardless, ZAF-corrected and SEC-factor corrected quantification of the acquired EDS spectra. The uncertainty of the quantification was estimated by measuring the carbon concentration at different acceleration voltages from the same areas of 3 spent catalyst particles from each experiment 10 and 11 (see Table 2 and supplementary information Figure S.1 and Table S.3). This showed that the standard deviation for the carbon measurement was $1.5 \mathrm{wt} . \%$ at $3 \mathrm{kV}$, $0.8 \mathrm{wt} . \%$ at $5 \mathrm{kV}, 1.0 \mathrm{wt.} \%$ at $10 \mathrm{kV}$, and $1.5 \mathrm{wt} . \%$ at $15 \mathrm{kV}$. The measured carbon content on the fresh and spent catalysts are shown in Table S.4.

The transmission electron microscopy was performed on a FEI Talos ${ }^{\mathrm{TM}}$ F200X transmission electron microscope equipped with high-brightness field emission gun (X-FEG) and Super-X G2 EDS detector. The sample was crushed in a mortar and dispersed dry on a CU-TEM grid covered with a continuous carbon film (SPI supplies). Images and elemental EDS maps were acquired in scanning transmission mode (STEM) with a camera length of $125 \mathrm{~cm}$. Elemental EDS maps of $2.1 \mu \mathrm{m} \times 2.1 \mu \mathrm{m}$ (512 pixels $\times 512$ pixels) were acquired for 5 min in Brüker software (Esprit 1.9) using a probe current of $0.7 \mathrm{nA}$. The elemental EDS maps were 
processed in Esprit with a smoothing filter ( $3 \times 3)$ and selected elements $(\mathrm{Fe}, \mathrm{O}, \mathrm{S}, \mathrm{Al}, \mathrm{Si})$ were displayed as total counts of the $K_{\alpha}$-lines, respectively. The full spectra are shown in Supplementary Information Figures S.2 and S.3. The relative composition at selected areas were determined in the Brüker software using peak fit by series deconvolution and Cliff-Lorimer quantification.

\section{Results and Discussion}

\subsection{Effect of catalyst in fluid bed on the product distribution}

The process conditions and the mass balances for all the conducted experiments are shown in Table 2. The data from experiments 1 and 2 have previously been published [38], and are used as benchmarks in this work. In experiments 7 and 8 the catalyst in the fluid bed was not sulfided. In experiment 7 the catalyst in the HDO reactor was maintained in the sulfided state by adding the $\mathrm{H}_{2} \mathrm{~S}$ to the gas after the fluid bed reactor. The OS and ZA bed materials were not sulfided prior to the experiments. When MgAl and OS were used as catalysts the temperature in the fluid bed reactor decreased when the biomass feeding started, see supplementary information Figure S.4, indicating that the exothermic hydrodeoxygenation reactions only occurred to a limited degree and that the hydropyrolysis overall was endothermic. The opposite was observed with the rest of the catalysts where the hydropyrolysis overall was exothermic.

The total mass balance varied between 71.3 and $101 \mathrm{wt} . \%$ daf (see Table 1), where particularly experiment 4 using OS as bed material resulted in low recovery. In experiment 4, when the OS was tested, the tube between the fluid bed and filter was blocked after 45 minutes of operation. This was most likely due to biooil condensation in the pipe, which lead to char build up which consequently lead to blocking of the pipe. Thus, it was not possible to estimate the char yield for this experiment resulting in the very low mass recovery. The technical difficulties using OS as bed material, combined with the observation that using OS leads to an overall endothermic reaction in the fluid bed, indicates that OS is not a suitable catalyst for catalytic hydropyrolysis. Consequently, the experiment was not repeated. Using ZA lead to defluidization of 
the bed after $85 \mathrm{~min}$, which is the reason for the poor mass balance of $91.3 \mathrm{wt} . \%$ daf for experiment 9 . The mass balances in the remaining experiments varied between 94.8 and $101 \mathrm{wt} . \%$ daf.

The $C_{1}-C_{3}$ gas yields were between 3.2 and 14.3 wt.\% daf, the $C O$ and $\mathrm{CO}_{2}$ yields were between 13.1 and 20.0 wt.\% daf, the condensed organics and $\mathrm{C}_{4+}$ yields were between 15.8 and $34.1 \mathrm{wt} . \%$ daf, and the char and coke yields were between 10.5 and $21.1 \mathrm{wt} . \%$ daf. The carbon balance is shown in supplementary information Table S.5 and detailed gas yields are shown in supplementary information Table S.6. In order to evaluate the repeatability, experiments 10 and 11 were performed at similar conditions. The largest difference in the yields was for the aqueous phase, where the difference was $1.2 \mathrm{wt} . \%$ daf, however, the difference in the $\mathrm{C}_{1}-\mathrm{C}_{3}$ yield was $<0.1$ wt.\% daf, $\mathrm{CO}$ and $\mathrm{CO}_{2}$ yield was $0.4 \mathrm{wt} . \%$ daf, char and coke yield was $0.1 \mathrm{wt} . \%$ daf, and the condensed organics and $\mathrm{C}_{4+}$ in the gas yield was $0.1 \mathrm{wt} . \%$ daf. Furthermore, only a small difference in the char and coke yield ( 0.4 wt.\% daf) was observed between experiment 5 and 6 where the same catalyst was used in the HDO reactor. It is therefore assumed that the experimental error is less than $0.5 \mathrm{wt} . \%$ daf for the char and coke yield, $0.2 \mathrm{wt} . \%$ daf for the $\mathrm{C}_{1}-\mathrm{C}_{3}$ yield, $0.5 \mathrm{wt} . \%$ daf for the total CO and $\mathrm{CO}_{2}$ yield, $1.5 \mathrm{wt} . \%$ for the aqueous phase yield, and less than $0.5 \mathrm{wt} . \%$ daf for the condensed organics and $\mathrm{C}_{4+}$ in the gas yield. However, the uncertainly also depends on the mass balance, thus the uncertainty is most likely higher for the experiment with OS (experiment 4) and ZA (experiment 9). A larger difference in the char and coke yield ( $2.1 \mathrm{wt} . \%$ daf) was observed between experiment 7 and 8 . This was because the spent catalyst in experiment 7 was not oxygen passivated prior to unloading the fluid bed reactor, thus it self-ignited when exposed to air during the unloading, which combusted some of the char, decreasing the char yield.

The energy recovery was calculated on the basis of the higher heating value (HHV) of the biomass fed to the setup and the HHV of the different phases. The heating value of the gas was calculated on the basis of the heating value of the different compounds detected in the gas, and the heating value of the condensed organics was calculated on the basis of its elemental (CHNSO) composition according to ref. [40]. The 
energy recovery in the condensed organics and $\mathrm{C}_{4+}$ was between 34 and $61 \%$. Using OS in the fluid bed (experiment 4) gave the lowest energy recovery (34\%), while the highest values were obtained when BI-R was used in the fluid bed: $58 \%$ when the HDO reactor was used (experiment 7) and $61 \%$ when the HDO reactor was not used (experiment 8). Using the pure support materials MgAl (experiment 3) and ZA (experiment 9) gave a lower energy recovery, between 42 and $45 \%$, compared to when the supported catalysts CoMo (experiment 1) and NiMoZA (experiment 10 and 11) were used, between 51 and $54 \%$.

The char and coke, gas, aqueous phase, and condensable organics yields for the experiments, where both the fluid bed and the HDO reactor are used, are shown in Figure 2. Using the pure support materials MgAl and ZA lead to a high char and coke yield of 18.9 and $21.2 \mathrm{wt} . \%$ daf, respectively. Using the supported catalysts significantly decreased the char and coke yield to 11.4 wt.\% daf for the CoMo and between 13.1 and 13.0 wt.\% daf for the NiMoZA, indicating that the active catalysts stabilized the pyrolysis vapors before secondary coke forming reactions took place. Using BI-S and BI-R gave a char yield of 13.5 and 12.7 wt.\% daf, respectively. Remarkably the $\mathrm{C}_{1}-\mathrm{C}_{3}$ gas yield was almost the same when using OS (8.9 wt.\% daf), MgAl (9.0 wt.\% daf), and ZA ( 8.6 wt.\% daf). The $\mathrm{CO}$ and $\mathrm{CO}_{2}$ yield for these three catalysts were also almost the same: 18.7 wt.\% daf when using OS, 18.9 wt.\% daf when using MgAl, and 20.0 wt.\% daf when using ZA. However, the aqueous phase and condensable organics yields seemingly varied for these materials. This could be due to the large differences in how well the mass balance closed. Using the supported active catalysts (experiment 1, 10 and 11 ) increased the $C_{1}-C_{3}$ yield, but decreased the total $\mathrm{CO}$ and $\mathrm{CO}_{2}$ yield due to less cracking and more hydrogenation activity.

Using $\mathrm{BI}-\mathrm{S}$ and $\mathrm{BI}-\mathrm{R}$ lead to a low $\mathrm{C}_{1}-\mathrm{C}_{3}$ yield; 11.2 wt.\% daf when using $\mathrm{BI}-\mathrm{S}$ and 11.6 wt.\% daf when using $\mathrm{BI}-\mathrm{R}$. Furthermore, both catalysts also have a low total $\mathrm{CO}$ and $\mathrm{CO}_{2}$ yield; $14.0 \mathrm{wt} . \%$ daf when using the $\mathrm{BI}-\mathrm{S}$ and 13.1 wt.\% daf when using BI-R. BI-R also has the highest aqueous phase yield (41.3 wt.\%), while it was lower when using the BI-S (36.3 wt. \%). Comparing the char and coke yield for BI-R in experiment 8 (12.7 wt.\%) with the char yield for BI-S in experiment 5 (13.5 wt.\%) and 6 (13.1 wt.\%) indicates that the catalysts 
produces the same amount of char and coke. Comparing the aqueous phase yields with the total $\mathrm{CO}$ and $\mathrm{CO}_{2}$ yields in the experiments where the $\mathrm{HDO}$ reactor is used (experiment $1,2,3,4,5,7,9,10,11$ ) indicates that using an active catalyst in the fluid bed reactor gives a low total $\mathrm{CO}$ and $\mathrm{CO}_{2}$ yield and a high aqueous phase yield. Considering that the condensable organics is essentially oxygen free when the HDO reactor is used this correlation is expected. For both MgAl and ZA an increase in the condensable organics yield was observed using the supported catalysts (experiment 1, 10 and 11) compared with the pure support materials (experiment 3 and 9). Using MgAl gave a condensed organics and $\mathrm{C}_{4+}$ yield of 17.8 wt.\% daf, which increased to 21.5 wt.\% daf when the CoMo was used, and using ZA gave a condensed organics and $\mathrm{C}_{4+}$ yield of 20.3 wt.\% daf, which increased to 23.9-24.0 wt.\% daf when using NiMoZA. Interestingly, the condensed organics and $\mathrm{C}_{4+}$ yield was 24.7 wt.\% daf for $\mathrm{BI}-\mathrm{R}$ (experiment 7) and 22.8 wt.\% daf for $\mathrm{BI}-\mathrm{S}$ (experiment 5) when the HDO reactor was used, showing that it is favorable to run the $\mathrm{BI}$ as a reduced catalyst instead of as a sulfided catalyst.

The effect of bypassing the HDO reactor is shown in Figure 3, where the product distribution is shown for experiments with and without the HDO reactor when CoMo, BI-S and $\mathrm{BI}-\mathrm{R}$ is used in the fluid bed reactor. For all the catalysts a decrease in the total $\mathrm{C}_{1}-\mathrm{C}_{3}$ and total $\mathrm{CO}$ and $\mathrm{CO}_{2}$ yields were observed when the HDO reactor was bypassed, showing that cracking reactions take place in the HDO reactor. This trend was pronounced when $\mathrm{BI}-\mathrm{R}$ and $\mathrm{BI}-\mathrm{S}$ were tested without the $\mathrm{HDO}$ reactor. For $\mathrm{BI}-\mathrm{R}$ and $\mathrm{BI}-\mathrm{S}$ the $\mathrm{C}_{1}-\mathrm{C}_{3}$ yields were only $3.2 \mathrm{wt} . \%$ daf and $4.3 \mathrm{wt} . \%$ daf, respectively, and the total $\mathrm{CO}$ and $\mathrm{CO}_{2}$ yield was $14.1 \mathrm{wt} . \%$ daf for BI-R and 15.0 wt.\% daf for BI-S. This shows that BI-S and -R have a low cracking activity, which may be the reason for the high condensable organic yield observed when using these catalysts. The amount of $\mathrm{C}_{4+}$ also decreased and the amount of condensed organics increased when the HDO reactor was bypassed in the experiments with BI-S (experiment 6) and BI-R (experiment 8), in part due to a significant oxygen content.

The $\mathrm{CO}$ and $\mathrm{CO}_{2}$ yield and the $\mathrm{CO} / \mathrm{CO}_{2}$ ratio on molar basis is shown in Figure 4. The molar ratio between $\mathrm{CO}$ and $\mathrm{CO}_{2}$ is almost the same (between 1.5 and 1.8) when the HDO reactor is used. Bypassing the HDO 
reactor shows a significant difference between the CoMo and BI-S/R. The molar ratio between $\mathrm{CO}$ and $\mathrm{CO}_{2}$ was 3.1 for the CoMo, but 0.8 and 0.7 for $\mathrm{BI}-\mathrm{S}$ and $\mathrm{BI}-\mathrm{R}$, respectively. This indicates that when the CoMo is used in the fluid bed reactor water gas shift (see Equation (1)) takes place in the HDO reactor, but when BI$S / R$ is used in the fluid bed reactor, reverse water gas shift takes place in the HDO reactor instead. Since the $\mathrm{CO}$ and $\mathrm{CO}_{2}$ molar ratio is almost the same when the $\mathrm{HDO}$ reactor is used, this indicates that the water gas shift equilibrium is approached in the $\mathrm{HDO}$ reactor. A low $\mathrm{CO} / \mathrm{CO}_{2}$ ratio is preferable because this increases the relative oxygen removal compared to the amount of carbon lost to the gas phase, thus BI-S/R has a desirable $\mathrm{CO} / \mathrm{CO}_{2}$ selectivity compared to the CoMo catalyst.

$$
\mathrm{CO}+\mathrm{H}_{2} \mathrm{O} \rightleftharpoons \mathrm{CO}_{2}+\mathrm{H}_{2}
$$

\subsection{Chemical composition of the condensed liquids}

\subsubsection{Organic phase}

In the experiments were the HDO reactor was used the hydrogen content in the condensed organics was between 11.16 and 12.14 wt.\% db. Bypassing the HDO reactor decreased the hydrogen content from 11.93 to 10.22 wt.\% db when the CoMo was used in the fluid bed reactor. The hydrogen content when the HDO reactor was used was $11.65 \mathrm{wt} . \% \mathrm{db}$ for BI-S and $11.32 \mathrm{wt} . \% \mathrm{db}$ for BI-R, which decreased to $8.06 \mathrm{wt}$ \% $\mathrm{db}$ for BI-S and 8.83 wt.\% $\mathrm{db}$ for BI-R when the HDO reactor was bypassed. The reason for the lower hydrogen content when the HDO reactor was bypassed is the much lower extent of HDO as evidenced by the higher oxygen content. For CoMo the oxygen content was $1.8 \mathrm{wt} . \% \mathrm{db}$ when the HDO reactor was bypassed, while it was 22.1 and $14.1 \mathrm{wt} . \% \mathrm{db}$ for BI-S and BI-R, respectively.

The density at $40^{\circ} \mathrm{C}$ of the condensed organic phase was between 0.8253 and $0.8583 \mathrm{~g} / \mathrm{ml}$ when the HDO reactor was used, see Table 2. Bypassing the HDO reactor increased the density when using the CoMo catalyst from $0.8273 \mathrm{~g} / \mathrm{ml}$ to $0.8890 \mathrm{~g} / \mathrm{ml}$, from $0.8378 \mathrm{~g} / \mathrm{ml}$ to $1.0123 \mathrm{~g} / \mathrm{ml}$ when using BI-S and from 
0.8583 to $0.9822 \mathrm{~g} / \mathrm{ml}$ when using BI-R. Thus using the HDO reactor decreases the density of the organic phase. The high density of the organic phase when using BI-S and bypassing the HDO reactor (experiment 6) is due to the high water (17 wt.\%) and oxygen content ( $22.1 \mathrm{wt} . \% \mathrm{db})$ in the organic phase. Trinh et al [6] measured the density at $40{ }^{\circ} \mathrm{C}$ of conventional pyrolysis oil from wood to be $1.12 \mathrm{~g} / \mathrm{mL}$, which is significantly higher than the density of the organic phase in the experiments without the HDO reactor.

The kinematic viscosity of the produced organic phase was between 1.041 and 1.153 cSt when the HDO reactor was used. Bypassing the HDO reactor increased the kinematic viscosity to $1.607 \mathrm{cSt}$ when the CoMo catalyst was used and $4.668 \mathrm{cSt}$ when BI-R was used. Thus the kinematic viscosity increased with increasing oxygen content of the oil, as expected.

The simulated distillation curve for the condensed organics from the experiments where the HDO reactor was used is shown in Figure 5. Between 20 to 40 vol. \% of the condensed organics was naphtha, while the remaining was in the diesel boiling point range. The highest fraction of naphtha was obtained with the CoMo (40\%), while the lowest was obtained with the BI-R (20\%). However, it should be noted that the $\mathrm{C}_{4+}$ detected in the gas should be considered as naphtha, increasing its fraction to $60-70$ wt.\%. The NiMoZA catalyst produced the organics with the highest boiling point, while the MgAl produced organics with the lowest boiling point. The reason for the high boiling point when using NiMoZA could be that more alkylation took place when zeolite was mixed into the carrier, which is probably due to the acidity of the zeolite. Lai et al. [41] also observed that alkylation reactions occurred when upgrading the hydropyrolysis vapors at high temperature in a separate fluid bed reactor with a HDO catalyst.

The composition of the condensed organics was further investigated by GC×GC-MS/FID. On this basis the condensed organics can be divided into the following groups: paraffins (Par), naphthenes (Naph), monoaromatics (mAro), diaromatics (diAro), triaromatics (triAro), larger aromatics (tetAro+), oxygenated aliphatics (o-Ali), and phenols ( $\mathrm{PhOH})$. Furthermore the components are also divided into the following groups based on the number of carbon atoms in the components: less than 10 carbons atoms (-C10), 
between 11 and 15 carbons atoms (C11-C15), between 16 and 20 carbon atoms (C16-C20), and more than 20 carbon atoms (C20+). The composition of the organics for the experiments where the HDO reactor was used is shown in Figure 6. In some of the condensed organics phenol was observed. For MgAl (Figure 6 B) and $\mathrm{BI}-\mathrm{S}$ (Figure $6 \mathrm{D}$ ) this is most likely due to small impurities from previous experiments, while it could also be due to deactivation of the HDO reactor for ZA (Figure $6 \mathrm{~F}$ ) and NiMoZA (Figure $6 \mathrm{G}$ and H). The condensed organics from the experiment with the CoMo catalyst in the fluid bed (Figure 6 A) had the highest concentration of monoaromatics. The organics from the experiments with NiMoZA (Figure $6 \mathrm{G}$ and H) had almost the same total concentration of aromatics as for the CoMo, however, a larger fraction of them were diaromatics, triaromatics or larger aromatics, which also indicates that alkylation and condensation reactions took place over NiMoZA. The concentration of tri- and larger aromatics were low for MgAl (Figure $6 \mathrm{~B}-0.9 \%$ ) and ZA (Figure $6-1.9 \%$ ) compared to the supported active catalyst (CoMo: 3.2 \%, NiMoZA: 4.9-6.4 \%). Furthermore the concentration of naphthenes was higher for MgAl (Figure 6 B $49 \%$ ) compared to CoMo (Figure 6 A - $29 \%$ ) and for ZA (Figure 6 F - $41 \%$ ) compared to NiMoZA (Figure 6 G \& H - 34-30\%). The reason for this observation could be that the molecules that would have turned into aromatics in the experiments with CoMo and NiMoZA instead polymerized and turned into coke and char when MgAl and ZA were used. Using OS gave a high concentration of di-, tri- and larger aromatics compared to $\mathrm{MgAl}$ and $\mathrm{ZA}$. For $\mathrm{MgAl}$ and $\mathrm{ZA}$ the concentration of components with less than 10 carbon atoms were 50 and $52 \%$, respectively, however interestingly for OS it was only $34 \%$ that contained less than 10 carbon atoms.

There was a significant difference between the composition of the condensed organics for BI-S (Figure $6 \mathrm{D}$ ) and BI-R (Figure $6 \mathrm{E}$ ). The condensed organics from BI-S consisted of $44 \%$ naphthenes, while only $33 \%$ of the condensed organics from BI-R was naphthenes. The size of the components also varied, for $\mathrm{BI}-\mathrm{S} 52 \%$ of the components contained less than 10 carbon atoms, compared to $36 \%$ of the components for $\mathrm{BI}-\mathrm{R} .2 .0 \%$ of the components in the condensed organics for the experiment with BI-R had more than 20 carbon atoms, but for BI-R $8.4 \%$ of the components had more than 20 carbon atoms. This indicates that BI-S had a 
higher cracking activity than $\mathrm{BI}-\mathrm{R}$, which is also supported by the observed higher $\mathrm{C}_{1}-\mathrm{C}_{3}$ and $\mathrm{CO}$ and $\mathrm{CO}_{2}$ yield for BI-S than BI-R. The effect of the catalyst in the fluid bed reactor is compared on the basis of the type of compounds and the molecular size distribution in the condensed organic phase in supplementary information Figure S.5 and Figure S.6, respectively.

The composition of condensed organics from the experiments without the HDO reactor is shown in Figure 7. Comparing the CoMo with HDO (Figure $6 \mathrm{~A}$ ) to the CoMo without the HDO reactor (Figure $7 \mathrm{~A}$ ) shows that the number of carbon atoms in the size range C11-C15 increased and -C10 decreased when the HDO reactor was bypassed. In the experiment without the HDO reactor most of the oxygenates were phenols (area-FID: $22 \%$ ) but small amounts of oxygenated aliphatics (area-FID: $4 \%$ ) were also observed, showing that the CoMo was able to remove most of the oxygenated aliphatics. Small amounts of larger oxygenated aromatics (0.11\% FID-area), and traces of indoles (<1 ppm-wt) and Pyrroles ( $1 \mathrm{ppm}-\mathrm{wt})$ were also detected. Comparing the concentrations for the experiments where the HDO reactor was bypassed for BI-S (Figure $7 \mathrm{~B}$ ) and BI-R (Figure $7 \mathrm{C}$ ) to the experiments with the HDO reactor (Figure $6 \mathrm{D}$ and $\mathrm{E}$ ), shows that bypassing the HDO reactor decreased the concentration of naphthenes, mono and diaromatics, while increasing the concentration of larger aromatics and oxygenated hydrocarbons. The concentration of oxygenated aliphatics were significantly higher for BI-S (51 \% area-FID) and $\mathrm{BI}-\mathrm{R}$ (39\% area-FID) than the CoMo catalyst ( $4 \%$ area-FID). Furthermore the condensed organics from the experiment with $\mathrm{BI}-\mathrm{S}$ and $\mathrm{BI}-\mathrm{R}$ contained between 8 and $10 \%$ area-FID dihydroxybenzenes, which was not detected in the condensed organics from the experiment with the CoMo. Sterols were also detected in small amounts $(<0.2 \%$ areaFID) when the BI-S and BI-R catalysts were used. This shows that the BI-S and BI-R have a significantly lower deoxygenantion and hydrogenation activity compared to CoMo. The effect of the catalyst in the fluid bed reactor without the HDO reactor is compared on the basis on the type of compounds and the molecular size distribution in the condensed organic phase in supplementary information Figure S.7 and Figure S.8, respectively. 


\subsubsection{Aqueous phase}

The carbon yield and the hydrocarbon distribution in the aqueous phases from experiment 2 (CoMo), 6 (BIS) and $8(\mathrm{BI}-\mathrm{R})$ are shown in Figure 8 . The carbon yield in the aqueous phase from the experiment with the CoMo catalyst was 0.96 wt.\% daf, while the carbon yield in the aqueous phase when using BI-S and BI-R was 6.8 and 4.8 wt.\% daf, respectively. The higher carbon yield in the aqueous phase from the experiments with $\mathrm{BI}-\mathrm{S}$ and $\mathrm{BI}-\mathrm{R}$ compared to the experiment with CoMo is because of the higher oxygen concentration in the produced oil makes it more soluble in the aqueous phase. GC-MS/FID showed that the hydrocarbons in the aqueous phase from the experiment with the CoMo catalyst consisted of phenols, ketones and alcohols. For BI-S and BI-R ketones, ethers, phenols, alcohols, and acids were detected. Sugars were only detected when using BI-S and furans were only detected when using BI-R. The relative concentration (AreaFID (\%)) of phenols and alcohols were lower in the experiment with $\mathrm{BI}-\mathrm{S}$ and $\mathrm{BI}-\mathrm{R}$ compared to the experiment with CoMo. This is not because BI-S and BI-R were better at deoxygenating these molecules, but because the phenols are dissolved in the (more oxygen rich) organic phase. The organic phase also contained larger amounts of water when using the BI-S/R catalysts compared to the CoMo catalyst resulting in a larger partition coefficient for phenols in the organic phase. The detection of acids in the aqueous phase when using $\mathrm{BI}-\mathrm{R} / \mathrm{S}$ as catalysts indicates that conducting the catalytic hydropyrolysis without a second hydrotreating reactor could lead to storage problems for the liquid product.

\subsection{Characterization of the spent catalysts}

\subsubsection{SEM}

The spent catalysts from the fluid bed reactor were studied with SEM combined with EDS. Figure 9 shows the measured carbon content as a function of the electron acceleration voltage for the spent catalysts. The signal measured at $3 \mathrm{kV}$ corresponds to the surface of the sample (low penetration), while at $15 \mathrm{kV}$ the signal integrates the signal from surface towards the bulk of the sample. Comparing the carbon contents on the spent MgAl and CoMo (Figure $9 \mathrm{~A}$ ), shows that there was significantly less carbon on the spent CoMo 
(5.5-7.9 wt.\% at $15 \mathrm{keV}$ ) than $\mathrm{MgAl}(49 \mathrm{wt} . \%$ at $15 \mathrm{keV}$ ). Furthermore, the carbon concentration was relatively higher at the surface for $\mathrm{MgAl}(67 \mathrm{wt} . \%$ at $3 \mathrm{keV})$ than for CoMo (7.2-7.9 at $3 \mathrm{keV})$, suggesting a more even distribution of carbon on the CoMo. A similar trend was also observed when comparing ZA from experiment 9 with NiMoZA from experiment 10 and 11 (Figure 9 B), however, the trend was less pronounced in this case, as only half the amount of biomass was used in the experiment with ZA compared to the experiments with NiMoZA. An experiment with ZA was also conducted where $625 \mathrm{~g}$ of biomass (experiment \#12, which is not reported in Table 2) was used compared to $413 \mathrm{~g}$ in experiment 9, however, the experiment was conducted at similar conditions to experiment 9, but $\mathrm{H}_{2} \mathrm{~S}$ was not co-fed to the fluid bed in this experiment. Comparing these two spent ZA catalysts, and assuming that the $\mathrm{H}_{2} \mathrm{~S}$ did not have an impact on the catalyst, shows a significant increase in the amount of carbon on the spent catalyst when 625 $\mathrm{g}$ of biomass was used compared to $413 \mathrm{~g}$. This indicates that over time the pores in the ZA may be filled with carbon due to coking. A similar time effect are observed when comparing the spent CoMo from experiment 1 and 2, see Figure $1 \mathrm{~A}$, thus indicating that coking might also be an issue for supported catalysts, but much longer operating time is required to show this with certainty.

The spent OS (Figure 9 A) was the catalyst with most carbon on the surface (72 wt. \%). However, the average carbon content decreased to $23 \mathrm{wt} . \%$ as the acceleration voltage was increased to $15 \mathrm{kV}$, which is significantly less than the corresponding concentration of carbon for MgAl (49 wt. \%). This is possibly because MgAl has a significantly higher surface area (see Table 1), thus probably also a larger pore volume than OS, so more carbon can be accumulated in the bulk. The lower carbon concentration in the bulk than on the surface, which is observed for both OS and MgAl, indicates that the catalyst over time can become covered by coke. The carbon content on the two BI-S catalysts varied between 0.6 and $7.6 \mathrm{wt} . \%$ and the carbon content on the two BI-R catalysts varied between 3.4 and $11 \mathrm{wt} . \%$, hence there was slightly more carbon on the reduced than the sulfided catalysts. 
These results show that having a supported catalyst in the fluid bed compared to the pure support or OS gave a lower degree of coking of the catalysts. This supports the hypothesis that that the catalyst can stabilize the reactive products from the fast pyrolysis, which otherwise would polymerize and deactivate the catalyst by coking. Furthermore, the low carbon content on the surface of BI-R and BI-S (Figure 9 B) shows that despite that $\mathrm{BI}$ has a lower activity than the CoMo they are able to stabilize the vapors before they can polymerize on the surface of the catalyst.

\subsubsection{X-ray diffraction}

In order to investigate the active phase for bog iron, the fresh bog iron (i.e. in its oxide form), BI-S (from exp. 6) and BI-R (from exp. 8) were analyzed with X-ray diffraction. The X-ray diffraction patterns are shown in Figure 10 and the Rietveld fitted concentration and size of the crystals are shown in Table 3. XRD on the fresh bog iron showed strong reflections of goethite $(\alpha-\mathrm{FeOOH})$ corresponding to a concentration of 96.3 wt.\% and reflections for siderite $\left(\mathrm{FeCO}_{3}\right)(3.2 \mathrm{wt} . \%)$ and $\mathrm{SiO}_{2}(1.3 \mathrm{wt} . \%)$. BI-S consisted mainly of pyrrhotite $\left(\mathrm{Fe}_{1-\mathrm{x}} \mathrm{S}\right)(74.5 \mathrm{wt} . \%)$ and troilite $(\mathrm{FeS})(11.0 \mathrm{wt} . \%)$, and smaller reflection from Pyrite $\left(\mathrm{FeS}_{2}\right)$ (1.5 wt.\%) was also observed. It is well-known that pyrrhotite $\left(\mathrm{Fe}_{1-\mathrm{x}} \mathrm{S}\right)$ can be formed from $\gamma$-FeOOH[36], thus pyrrhotite and troilite are probably formed from Goethite $(\alpha-\mathrm{FeOOH})$. Furthermore, pyrrhotite is well-known for its activity in coal liquefaction $[33,34,36,42]$ and is most likely also the active phase in the BI-S catalyst. The average crystallite size of the formed pyrrhotite was $20 \mathrm{~nm}$, and thus a fairly small crystallite size was obtained, which was desirable since smaller crystallites are expected to increase the activity [33]. Interestingly, Mochida et al. [33] studied the effect of sulfiding temperature on the pyrrhotite crystallite size and found that when sulfiding $\gamma-\mathrm{FeOOH}$ at $400-450^{\circ} \mathrm{C}$ the crystallite size was approximately $20 \mathrm{~nm}$, in good agreement with our results.

The X-ray diffraction pattern for $\mathrm{BI}-\mathrm{R}$ showed strong reflections for hematite $\left(\mathrm{Fe}_{2} \mathrm{O}_{3}\right)$ and magnetite $\left(\mathrm{Fe}_{3} \mathrm{O}_{4}\right)$ and minor reflections for $\mathrm{CaCO}_{3}$ and $\mathrm{Fe}$. Hematite was most likely formed from magnetite during the passivation of the catalyst prior to the unloading. The small crystallite size (12 $\mathrm{nm}$ ) of magnetite could be the reason for the high activity for BI-R. Magnetite has also been used for treatment of pyrolysis gas and 
was found to reduce the amount of acetic acid, phenols, catechol and non-aromatic ketones [43]. One of the advantages of magnetite is that it is magnetic [44,45], thus it might be possible to recover entrained catalyst by a magnet.

\subsubsection{STEM}

The spent BI-S (experiment 6) and BI-R (experiment 8) were studied with STEM (see Figure 11). The EDS element distribution of $\mathrm{BI}-\mathrm{S}$ reveals iron well distributed on the particles together with a coincident signal of sulfur (supplementary information Figure S.7), consistent with iron sulfides. The primary particle sizes for BI-S (Figure $11 \mathrm{~A}$ ) was between 10 and $30 \mathrm{~nm}$, thus the STEM images supports the crystallite size estimated by XRD (Table 3). The presence of an oxygen signal in the element map, most pronounced at the surfaces of iron sulfide particles, indicates that some oxidation of the catalyst has taken place after it was unloaded.

The iron and oxygen was well distributed on the spent BI-R catalyst (Figure 11 D\&F). Only negligible amounts of sulfur (<0.5wt.\%) was observed. The particle sizes were between 10-20 nm (Figure $11 \mathrm{E}$ ). However, some of the particles were encapsulated with a 2-3 nm surface layer. EDS analyses of the core and the surface layer indicated a higher oxygen-to-iron ratio at the surface of these particles compared to the core (Figure $11 \mathrm{G}$ ). Thus the STEM-HAADF images support the hypothesis that the hematite was formed from magnetite at the particle surfaces during the passivation of the catalyst.

Aluminum and silicon were detected in both BI-R and BI-S (Figure 11) and the EDS element distribution indicates that the concentration of these compounds was not uniform. Phosphorus, potassium, and calcium were also detected in the spent bog iron and the EDS elemental distribution (Figure S.2 and Figure S.3) indicated that these compounds were uniformly distributed in the particles. As aluminum, silicon, 
phosphorus, potassium, and calcium were also detected in the fresh bog iron with ICP-OES (Table S.3), it is not possible to determine if these compounds were also transferred from the biomass to the catalyst.

\section{Conclusion}

The effect of the catalyst in catalytic hydropyrolysis of beech wood was studied by testing six different bed materials in the fluid bed reactor showing the importance of an active catalyst. The fluid bed reactor was followed by a fixed bed reactor with a sulfided $\mathrm{NiMo} / \mathrm{Al}_{2} \mathrm{O}_{3}$ catalyst, which ensured that the condensed organics was almost oxygen free $(<0.2 \mathrm{wt} . \%)$ independent on the catalyst in the fluid bed. The product distributions varied significantly for the different bed materials. Using $\mathrm{MgAl}_{2} \mathrm{O}_{4}$ and zeolite $(\mathrm{H}-\mathrm{ZSM}-5)$ mixed with $\mathrm{Al}_{2} \mathrm{O}_{3}$ as bed materials produced large amounts of char (18.7-21.1 wt.\% daf), $\mathrm{CO}$ and $\mathrm{CO}_{2}(18.9$ and 20.0 wt.\% daf), and low amounts of condensed organics and $\mathrm{C}_{4+}(17.8-20.4$ wt.\% daf). Using the supported catalysts $\mathrm{CoMo} / \mathrm{MgAl}_{2} \mathrm{O}_{4}$ and $\mathrm{NiMo} /$ zeolite mixed with $\mathrm{Al}_{2} \mathrm{O}_{3}$ significantly decreased the char yield to between 11.4 and 13.1 wt.\% daf, while the condensed organics and $\mathrm{C}_{4+}$ yield increased to 21.5 wt.\% daf for the CoMo/ $\mathrm{MgAl}_{2} \mathrm{O}_{4}$ and 24.0 wt.\% daf for the NiMo/zeolite mixed with $\mathrm{Al}_{2} \mathrm{O}_{3}$. Furthermore, SEM-EDS analysis on spent catalysts showed that using a supported active catalyst significantly decreased the degree of coking compared to the pure supports. Interestingly, the most promising catalyst was the natural mineral bog iron, which had a condensed organics and $\mathrm{C}_{4+}$ yield of $24.7 \mathrm{wt} . \%$ daf when it was used in reduced form and 22.8 wt.\% daf when it was used in sulfided form. Thus bog iron can be used in the fluid bed reactor without the need to continuously add $\mathrm{H}_{2} \mathrm{~S}$ and it is at the same time fairly sulfur resistant since it is also active in its sulfide form. The carbon content on the spent bog iron catalysts were at the same level as on the spent supported catalysts, showing that it is active enough to suppress coking reactions. Furthermore, X-ray diffraction patterns and STEM imaging and EDS analysis of the spent bog iron catalysts indicated that the active phase for the sulfided bog iron was pyrrhotite and the active phase for the reduced bog iron was magnetite. It is notable, that entrainment of bog iron from the fluid bed, mixing into 
the char, is less problematic than for CoMo or NiMo catalysts because it has a low toxicity, and thus handling of the char-catalyst mixture becomes less problematic.

\section{Acknowledgments}

This work is part of the project "Hydrogen assisted catalytic pyrolysis for green fuels" conducted at The Department of Chemical and Biochemical Engineering at the Technical University of Denmark (DTU). The work was supported by The Danish Council for Strategic Research (now Innovation Fund Denmark, project 1305-00015B), The Programme Commission on Sustainable Energy and Environment. Funding from DTU is also gratefully acknowledged. The authors would also like to thank Nadia Luciw Ammitzbøll (Haldor Topsøe A/S) for fruitful discussions, Caroline Piper Hem (Haldor Topsøe A/S) for assistant with X-ray diffraction measurements, the Inorganic Analysis Department at Haldor Topsøe A/S for the elemental analysis of the bog iron and olivine sand by inductive coupled plasma optical emission spectroscopy (IPC-OES), and the Organic Analysis Department at Haldor Topsøe A/S for analysis of the organic phase

\section{References}

[1] U.S.E.I. Administration, Annual Energy Outlook 2017, (2017). http://www.eia.gov/outlooks/aeo/pdf/0383(2017).pdf.

[2] ESA, World Population Prospects The 2015 Revision, (2015). http://esa.un.org/unpd/wpp/Publications/Files/Key_Findings_WPP_2015.pdf.

[3] S. Sorrell, J. Speirs, R. Bentley, A. Brandt, R. Miller, Global oil depletion: A review of the evidence, Energy Policy. 38 (2010) 5290-5295. doi:10.1016/j.enpol.2010.04.046.

[4] Core Writing Team, R.K. Pachauri, L.A. Meyers, Climate change 2014: Synthesis report, IPCC, Geneva, 2014. http://www.ipcc.ch/pdf/assessment-report/ar5/syr/SYR_AR5_FINAL_full.pdf. 
[5] A.V. Bridgwater, Review of fast pyrolysis of biomass and product upgrading, Biomass and Bioenergy. 38 (2012) 68-94. doi:10.1016/j.biombioe.2011.01.048.

[6] T.N. Trinh, P.A. Jensen, K. Dam-Johansen, N.O. Knudsen, H.R. Sørensen, S. Hvilsted, Comparison of lignin, macroalgae, wood, and straw fast pyrolysis, Energy \& Fuels. 27 (2013) 1399-1409. doi:10.1021/ef301927y.

[7] S. Czernik, A.V. Bridgwater, Overview of applications of biomass fast pyrolysis oil, Energy \& Fuels. 18 (2004) 590-598. doi:10.1021/Ef034067u.

[8] A. Oasmaa, S. Czernik, Fuel oil quality of biomass pyrolysis oils-State of the art for the end users, Energy \& Fuels. 13 (1999) 914-921. doi:10.1021/ef980272b.

[9] D. Chiaramonti, A. Oasmaa, Y. Solantausta, Power generation using fast pyrolysis liquids from biomass, Renew. Sustain. Energy Rev. 11 (2007) 1056-1086. doi:10.1016/j.rser.2005.07.008.

[10] D. Mohan, C.U. Pittman, P.H. Steele, Pyrolysis of wood/biomass for bio-oil: A critical review, Energy \& Fuels. 20 (2006) 848-889. doi:10.1021/ef0502397.

[11] R.H. Venderbosch, W. Prins, Fast pyrolysis technology development, Biofuels, Bioprod. Biorefining. 4 (2010) 178-208. doi:10.1002/bbb.205.

[12] P.M. Mortensen, J.-D. Grunwaldt, P.A. Jensen, K.G. Knudsen, A.D. Jensen, A review of catalytic upgrading of bio-oil to engine fuels, Appl. Catal. A Gen. 407 (2011) 1-19. doi:10.1016/j.apcata.2011.08.046.

[13] P.M. Mortensen, PhD Thesis: Catalytic Conversion of Bio-oil to Fuel for Transportation, Technical University of Denmark, Dept. of Chemical and Biochemical Engineering, 2013.

[14] M.R. Hurt, J.C. Degenstein, P. Gawecki, D.J. Borton II, N.R. Vinueza, L. Yang, R. Agrawal, W.N. Delgass, F.H. Ribeiro, H.I. Kenttämaa, On-line mass spectrometric methods for the determination of 
the primary products of fast pyrolysis of carbohydrates and for their gas-phase manipulation, Anal. Chem. 85 (2013) 10927-10934. doi:10.1021/ac402380h.

[15] R.H. Venderbosch, A Critical View on Catalytic Pyrolysis of Biomass, ChemSusChem. 8 (2015) 13061316. doi:10.1002/cssc.201500115.

[16] T.L. Marker, L.G. Felix, M.B. Linck, M.J. Roberts, Integrated hydropyrolysis and hydroconversion (IH $\left.{ }^{2}\right)$ for the direct production of gasoline and diesel fuels or blending components from biomass, Part 1: Proof of principle testing, Environ. Prog. Sustain. Energy. 31 (2012) 191-199. doi:10.1002/ep.10629.

[17] T.L. Marker, L.G. Felix, M.B. Linck, M.J. Roberts, P. Ortiz-Toral, J. Wangerow, Integrated hydropyrolysis and hydroconversion $\left(\mathrm{IH}^{2^{\circ}}\right)$ for the direct production of gasoline and diesel fuels or blending components from biomass, Part 2: Continuous testing, Environ. Prog. Sustain. Energy. 33 (2014) 762-768. doi:10.1002/ep.11906.

[18] D.C. Dayton, J. Carpenter, J. Farmer, B. Turk, R. Gupta, Biomass hydropyrolysis in a pressurized fluidized bed reactor, Energy \& Fuels. 27 (2013) 3778-3785. doi:10.1021/ef400355t.

[19] T. Van Nguyen, L.R. Clausen, Thermodynamic analysis of polygeneration systems based on catalytic hydropyrolysis for the production of bio-oil and fuels, Energy Convers. Manag. 171 (2018) 16171638. doi:10.1016/j.enconman.2018.06.024.

[20] D.C. Dayton, J. Hlebak, J.R. Carpenter, K. Wang, O.D. Mante, J.E. Peters, Biomass hydropyrolysis in a fluidized bed reactor, Energy \& Fuels. 30 (2016) 4879-4887. doi:10.1021/acs.energyfuels.6b00373.

[21] K. Wang, D.C. Dayton, J.E. Peters, O.D. Mante, Reactive catalytic fast pyrolysis of biomass to produce high-quality bio-crude, Green Chem. 19 (2017) 3243-3251. doi:10.1039/C7GC01088E.

[22] V.K. Venkatakrishnan, W.N. Delgass, F.H. Ribeiro, R. Agrawal, Oxygen removal from intact biomass to produce liquid fuel range hydrocarbons via fast-hydropyrolysis and vapor-phase catalytic 
hydrodeoxygenation, Green Chem. 17 (2015) 178-183. doi:10.1039/c4gc01746c.

[23] V.K. Venkatakrishnan, J.C. Degenstein, A.D. Smeltz, W.N. Delgass, R. Agrawal, F.H. Ribeiro, Highpressure fast-pyrolysis, fast-hydropyrolysis and catalytic hydrodeoxygenation of cellulose: Production of liquid fuel from biomass, Green Chem. 16 (2014) 792-802. doi:10.1039/c3gc41558a.

[24] L. Zhang, K. Gong, J. Lai, P. Alvey, Chemical composition and stability of renewable hydrocarbon products generated from a hydropyrolysis vapor upgrading process, Green Chem. 19 (2017) 36283641. doi:10.1039/C7GC01075C.

[25] F. Melligan, M.H.B. Hayes, W. Kwapinski, J.J. Leahy, Hydro-pyrolysis of biomass and online catalytic vapor upgrading with Ni-ZSM-5 and Ni-MCM-41, Energy \& Fuels. 26 (2012) 6080-6090. doi:10.1021/ef301244h.

[26] F. Melligan, M.H.B. Hayes, W. Kwapinski, J.J. Leahy, A study of hydrogen pressure during hydropyrolysis of Miscanthus $x$ giganteus and online catalytic vapour upgrading with Ni on ZSM-5, J. Anal. Appl. Pyrolysis. 103 (2013) 369-377. doi:10.1016/j.jaap.2013.01.005.

[27] D.P. Gamliel, L. Wilcox, J.A. Valla, The effects of catalyst properties on the conversion of biomass via catalytic fast hydropyrolysis, Energy \& Fuels. 31 (2017) 679-687. doi:10.1021/acs.energyfuels.6b02781.

[28] D.P. Gamliel, G.M. Bollas, J.A. Valla, Bifunctional Ni-ZSM-5 catalysts for the pyrolysis and hydropyrolysis of biomass, Energy Technol. 5 (2017) 172-182. doi:10.1002/ente.201600136.

[29] D.P. Gamliel, G.M. Bollas, J.A. Valla, Two-stage catalytic fast hydropyrolysis of biomass for the production of drop-in biofuel, Fuel. 216 (2018) 160-170. doi:10.1016/j.fuel.2017.12.017.

[30] F. Bergius, J. Billwiller, Process for producing liquid or soluble organic combinations from hard coal and the like., US Patent 1,251,954, 1918. 
[31] F. Bergius, Process for distilling and liquefying coal, US Patent 1,669,439, 1928.

[32] Friedrich Bergius, Chemical reactions under high pressure, Nobel Lect. (1932) 33.

[33] I. Mochida, K. Sakanishi, N. Suzuki, M. Sakurai, Y. Tsukui, T. Kaneko, Progresses of coal liquefaction catalysts in Japan, 2 (1998) 17-30.

[34] Y. Nakao, S. Yokoyama, Y. Maekawa, K. Kaeriyama, Coal liquefaction by colloidal iron sulphide catalyst, Fuel. 63 (1984) 721-722. doi:10.1016/0016-2361(84)90176-5.

[35] S. Yokoyama, R. Yoshida, H. Narita, K. Kodaira, Y. Maekawa, Catalytic activity of various iron sulphides in coal liquefaction, Fuel. 65 (1986) 164-170. doi:10.1016/0016-2361(86)90002-5.

[36] T. Kaneko, K. Tazawa, N. Okuyama, M. Tamura, Effect of highly dispersed iron catalyst on direct liquefaction of coal, 79 (2000) 263-271.

[37] J. Dilcio Rocha, C. a. Luengo, C.E. Snape, The scope for generating bio-oils with relatively low oxygen contents via hydropyrolysis, Org. Geochem. 30 (1999) 1527-1534. doi:10.1016/S01466380(99)00124-2.

[38] M.Z. Stummann, M. Høj, C.B. Schandel, A.B. Hansen, P. Wiwel, J. Gabrielsen, P.A. Jensen, A.D. Jensen, Hydrogen assisted catalytic biomass pyrolysis. Effect of temperature and pressure, Biomass and Bioenergy. 115 (2018) 97-107. doi:10.1016/j.biombioe.2018.04.012.

[39] Q. Wu, L.D.L. Duchstein, G.L. Chiarello, J.M. Christensen, C.D. Damsgaard, C.F. Elkj??r, J.B. Wagner, B. Temel, J.D. Grunwaldt, A.D. Jensen, In situ observation of Cu-Ni alloy nanoparticle formation by Xray diffraction, X-ray absorption spectroscopy, and transmission electron microscopy: Influence of Cu/Ni ratio, ChemCatChem. 6 (2014) 301-310. doi:10.1002/cctc.201300628.

[40] W.G. Lloyd, D.A. Davenport, Applying thermodynamics to fossil fuels: Heats of combustion from elemental compositions, J. Chem. Educ. 57 (1980) 56-60. doi:10.1021/ed057p56. 
[41] J. Lai, L. Zhang, K. Gong, Nuclear magnetic resonance characterization of renewable products from a two-step ex-situ hydropyrolysis vapor upgrading process, ChemistrySelect. 3 (2018) 297-307. doi:10.1002/slct.201702431.

[42] H.F. Ades, A.L. Companion, K.R. Subbaswamy, Molecular orbital calculations for iron catalysts, Energy \& Fuels. 8 (1994) 71-76. doi:10.1021/ef00043a012.

[43] P.H. Moud, E. Kantarelis, K.J. Andersson, K. Engvall, Biomass pyrolysis gas conditioning over an ironbased catalyst for mild deoxygenation and hydrogen production, Fuel. 211 (2018) 149-158. doi:10.1016/j.fuel.2017.09.062.

[44] S. Bae, S. Gim, H. Kim, V. Dorcet, M. Pasturel, J.M. Grenèche, G.K. Darbha, K. Hanna, New Features and Uncovered Benefits of Polycrystalline Magnetite as Reusable Catalyst in Reductive Chemical Conversion, J. Phys. Chem. C. 121 (2017) 25195-25205. doi:10.1021/acs.jpcc.7b08178.

[45] V.N. Nikiforov, Y.A. Koksharov, S.N. Polyakov, A.P. Malakho, A. V. Volkov, M.A. Moskvina, G.B. Khomutov, V.Y. Irkhin, Magnetism and Verwey transition in magnetite nanoparticles in thin polymer film, J. Alloys Compd. 569 (2013) 58-61. doi:10.1016/j.jallcom.2013.02.059. 


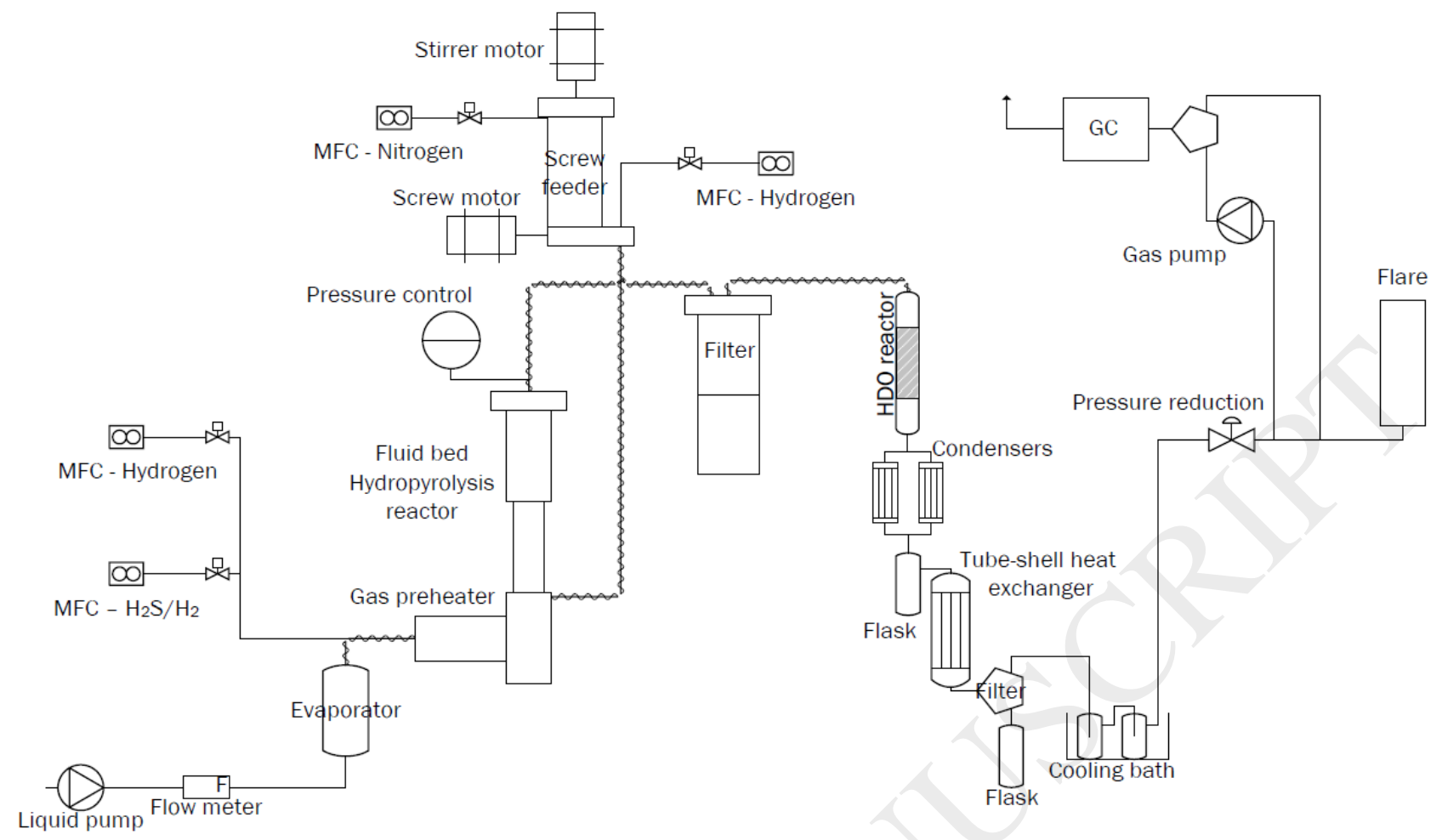

Figure 1. Simplified piping and instrumentation diagram of the fluid bed hydropyrolysis setup 


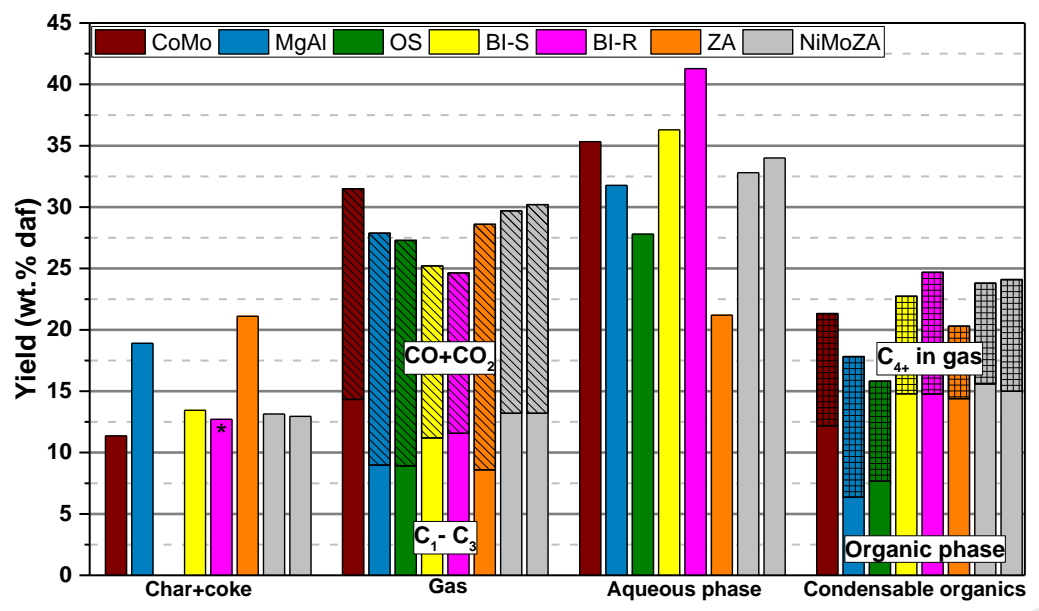

Figure 2 Effect of the catalyst on the product distribution when the HDO reactor is used. *The char yield from the experiment with BI-R is shown from experiment (\#8) without the HDO reactor. (Fluid bed temperature: $443-454{ }^{\circ} \mathrm{C}$, HDO temperature: 370 $394{ }^{\circ} \mathrm{C}$, pressure: 26 bar, biomass feeding rate: $174-302 \mathrm{~g} / \mathrm{h}, \mathrm{H}_{2} \mathrm{~S}$ concentration: 0-471 ppm, $\mathrm{H}_{2}$ flow: 54.4-89.2NL/min, $\mathrm{N}_{2}$ flow: $0.62-5 \mathrm{NL} / \mathrm{min}$ ) 


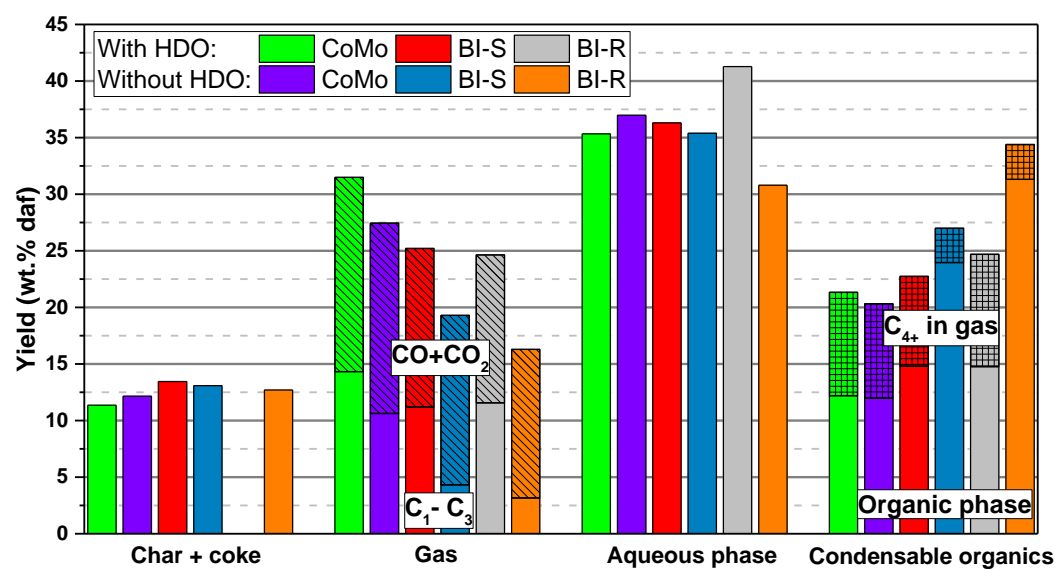

Figure 3. Product distribution with and without HDO reactor. (Fluid bed temperature: $450-454{ }^{\circ} \mathrm{C}$, pressure: 26 bar, biomass feeding rate: 174-302 $\mathrm{g} / \mathrm{h}, \mathrm{H}_{2} \mathrm{~S}$ concentration: 0-470 ppm, $\mathrm{H}_{2}$ flow: 87.4-89.2NL/min, $\mathrm{N}_{2}$ flow: 0.62-5 NL/min). 


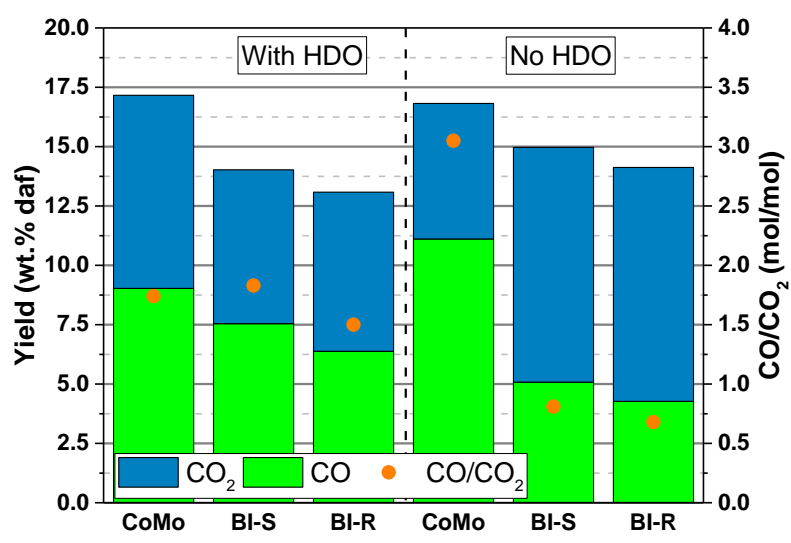

Figure 4. Effect of bypassing the $\mathrm{HDO}$ reactor on the $\mathrm{CO}$ and $\mathrm{CO}_{2}$ yield and the $\mathrm{CO}$ and $\mathrm{CO}_{2}$ ratio. (Fluid bed temperature: $450-454$ ${ }^{\circ} \mathrm{C}$, HDO temperature: $371-394{ }^{\circ} \mathrm{C}$, pressure: 26 bar, biomass feeding rate: $174-302 \mathrm{~g} / \mathrm{h}, \mathrm{H}_{2} \mathrm{~S}$ concentration: 0-470 ppm, $\mathrm{H}_{2}$ flow: 87.4-89.2NL/min, $\mathrm{N}_{2}$ flow: $0.62-5 \mathrm{NL} / \mathrm{min}$ ). 


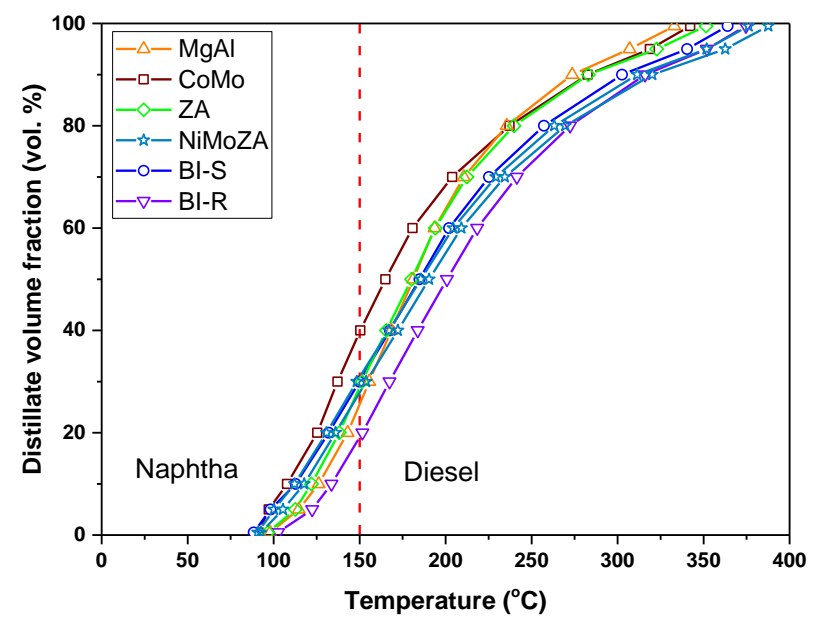

Figure 5 Simulated distillation of the condensed organics from experiments 1, 3, 4, 5, 7, 9, 10 and 11 . (Fluid bed temperature: 443-454 ${ }^{\circ} \mathrm{C}$, HDO temperature: $370-394{ }^{\circ} \mathrm{C}$, pressure: 26 bar, biomass feeding rate: $174-302 \mathrm{~g} / \mathrm{h}, \mathrm{H}_{2} \mathrm{~S}$ concentration: 0-471 ppm, $\mathrm{H}_{2}$ flow: $54.4-89.2 \mathrm{NL} / \mathrm{min}, \mathrm{N}_{2}$ flow: $0.62-5 \mathrm{NL} / \mathrm{min}$ ) 

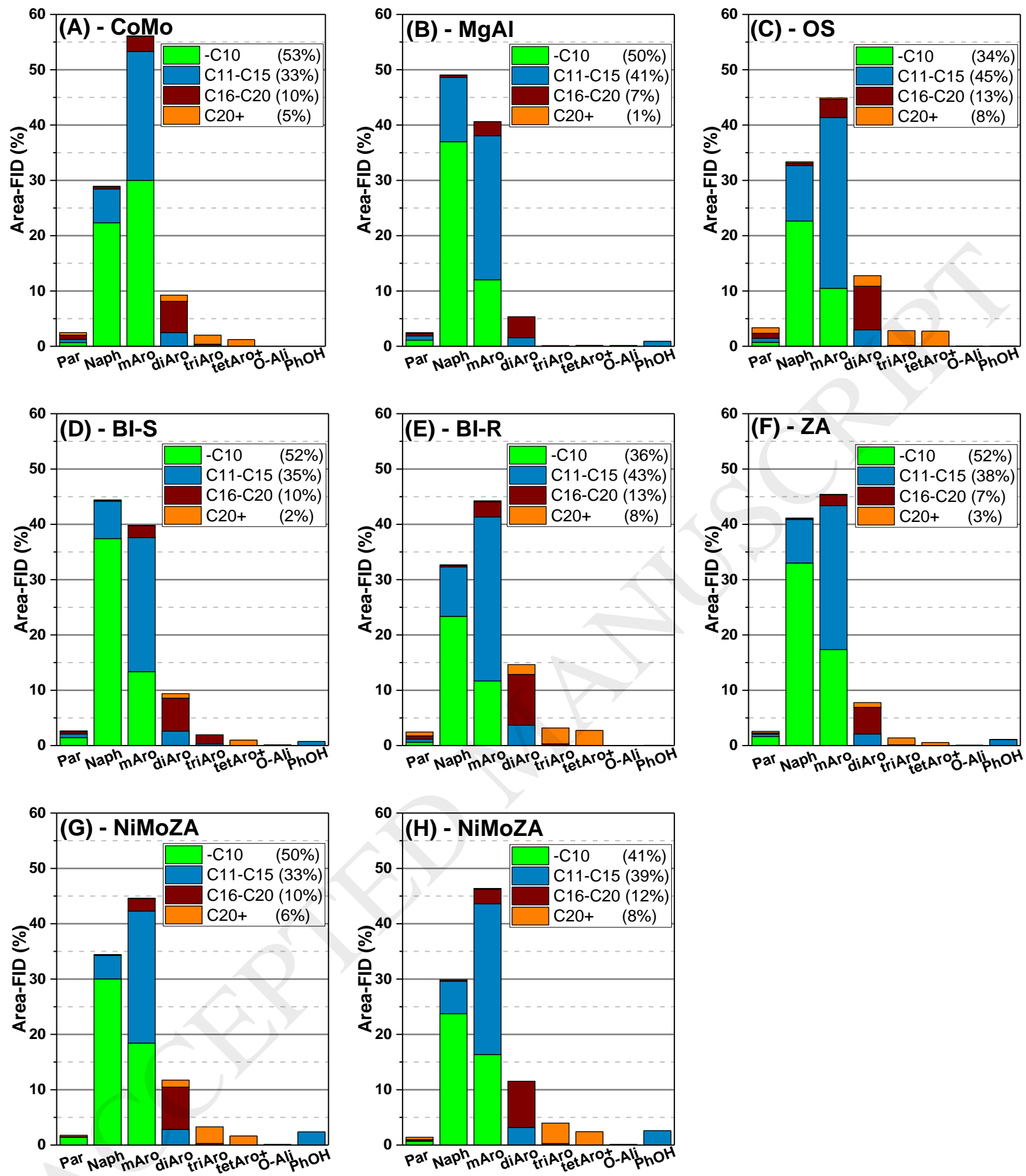

Figure 6 The composition of the condensed organic phase from experiment 1 (A), experiment 3 (B), experiment 4 (C), experiment $5(D)$, experiment $7(E)$, experiment $9(F)$, experiment $10(G)$ and experiment $11(H)$. The components in the condensed organics are divided into paraffins (Par), naphthenes (Naph), monoaromatics (mAro), diaromatics (diAro), triaromatics (triAro), tetraaromatics and larger aromatics (tetAro+), oxygenated aliphatics (O-Ali) and phenols (PhOH). The components are also divided into the following groups based on the number of carbon atoms in the components: less than 10 carbons atoms (-C10) 
between 10 and 15 carbons atoms (C11-C15), between 15 and 20 carbon atoms (C16-C20), more than 20 carbon atoms (C20+). (Fluid bed temperature: $443-454{ }^{\circ} \mathrm{C}$, HDO temperature: $370-394{ }^{\circ} \mathrm{C}$, pressure: 26 bar, biomass feeding rate: $174-302 \mathrm{~g} / \mathrm{h}, \mathrm{H} 2 \mathrm{~S}$ concentration: 0-471 ppm, $\mathrm{H}_{2}$ flow: $54.4-89.2 \mathrm{NL} / \mathrm{min}, \mathrm{N}_{2}$ flow: $0.62-5 \mathrm{NL} / \mathrm{min}$ ) 

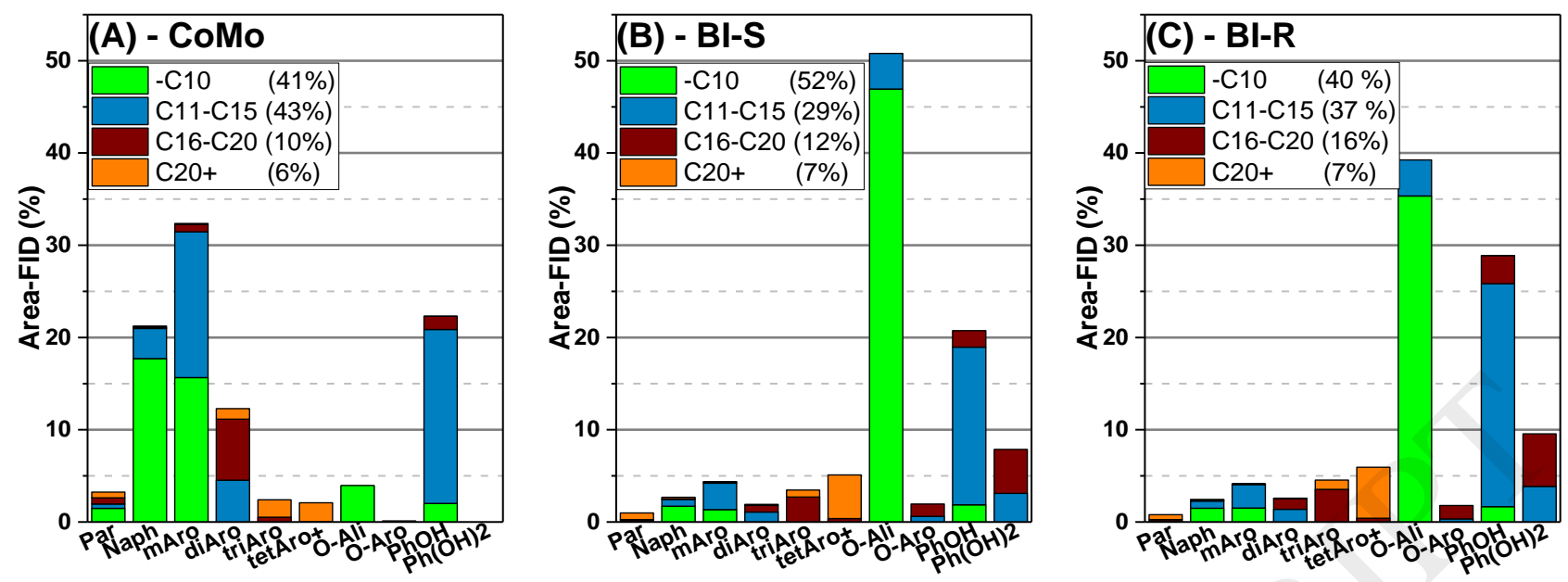

Figure 7 The composition of the condensed organic phase from experiment 2 (A), experiment 6 (B) and experiment 8 (C). The components in the condensed organics are divided into paraffins (Par), naphthenes (Naph), monoaromatics (mAro), diaromatics (diAro), triaromatics (triAro), tetraaromatics and larger aromatics (tetAro+), oxygenated aliphatics (O-Ali), phenols (PhOH), dihydroxybenzenes $(\mathrm{Ph}(\mathrm{OH}) 2)$, and oxygenated aromatics (O-Aro). The components are also divided into the following groups based on the number of carbon atoms in the components: less than 10 carbons atoms (-C10) between 10 and 15 carbons atoms (C11-C15), between 15 and 20 carbon atoms (C16-C20), more than 20 carbon atoms (C20+). (Fluid bed temperature: 450-454 ${ }^{\circ} \mathrm{C}$, pressure: 26 bar, biomass feeding rate: $174-302 \mathrm{~g} / \mathrm{h}, \mathrm{H}_{2} \mathrm{~S}$ concentration: 0-470 ppm, $\mathrm{H}_{2}$ flow: 87.4-89.2NL/min, $\mathrm{N}_{2}$ flow: 0.62-5 $\mathrm{NL} / \mathrm{min})$ 


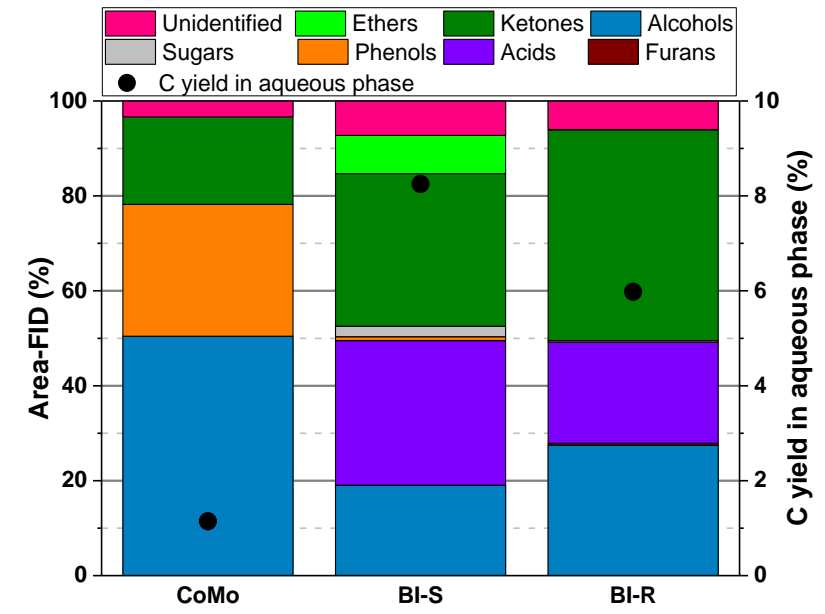

Figure 8 The total amount of carbon and composition of the hydrocarbons in the aqueous phase when the HDO reactor is bypassed (experiment 2, 6 and 8). (Fluid bed temperature: $450-454{ }^{\circ} \mathrm{C}$, pressure: 26 bar, biomass feeding rate: $174-302 \mathrm{~g} / \mathrm{h}, \mathrm{H}_{2} \mathrm{~S}$ concentration: 0-470 ppm, $\mathrm{H}_{2}$ flow: 87.4-89.2NL/min, $\mathrm{N}_{2}$ flow: 0.62-5 NL/min) 

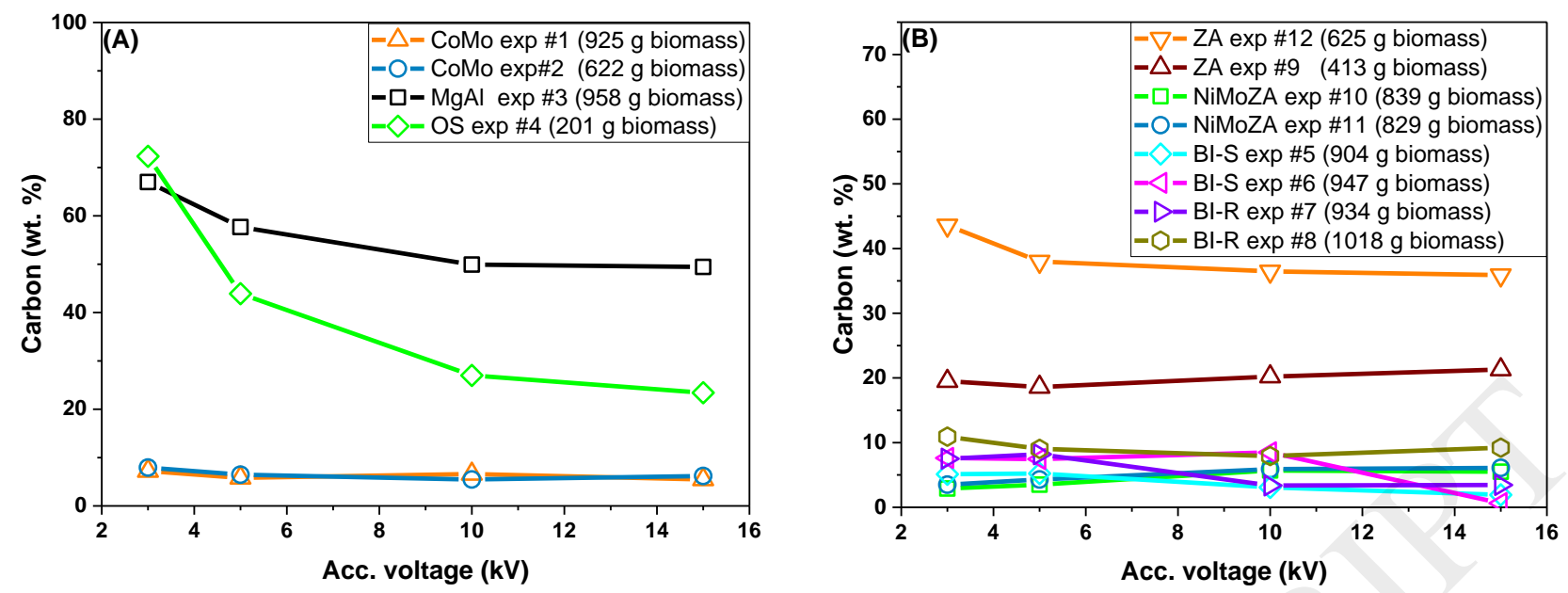

Figure 9. Carbon contents as a function of acceleration voltage on the spent CoMo, MgAl, and OS (A), ZA, NiMoZA, BI-S, and BI-R

(B). (Fluid bed temperature: $443-454{ }^{\circ} \mathrm{C}$, pressure: 26 bar, biomass feeding rate: $174-302 \mathrm{~g} / \mathrm{h}, \mathrm{H}_{2} \mathrm{~S}$ concentration: 0-471 ppm, $\mathrm{H}_{2}$ flow: $54.4-89.2 \mathrm{NL} / \mathrm{min}, \mathrm{N}_{2}$ flow: $0.62-5 \mathrm{NL} / \mathrm{min}$ ) 


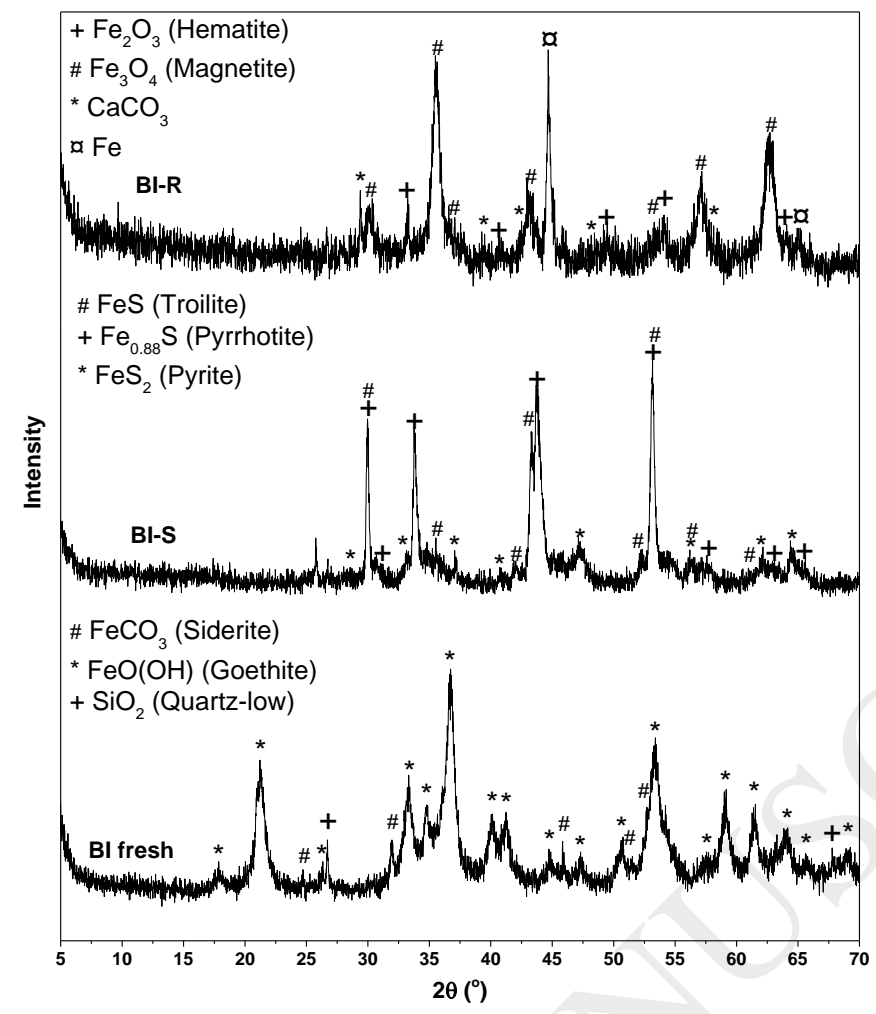

Figure 10 X-ray diffraction patterns for fresh BI, BI-S (experiment 6), and BI-R (experiment 8). 

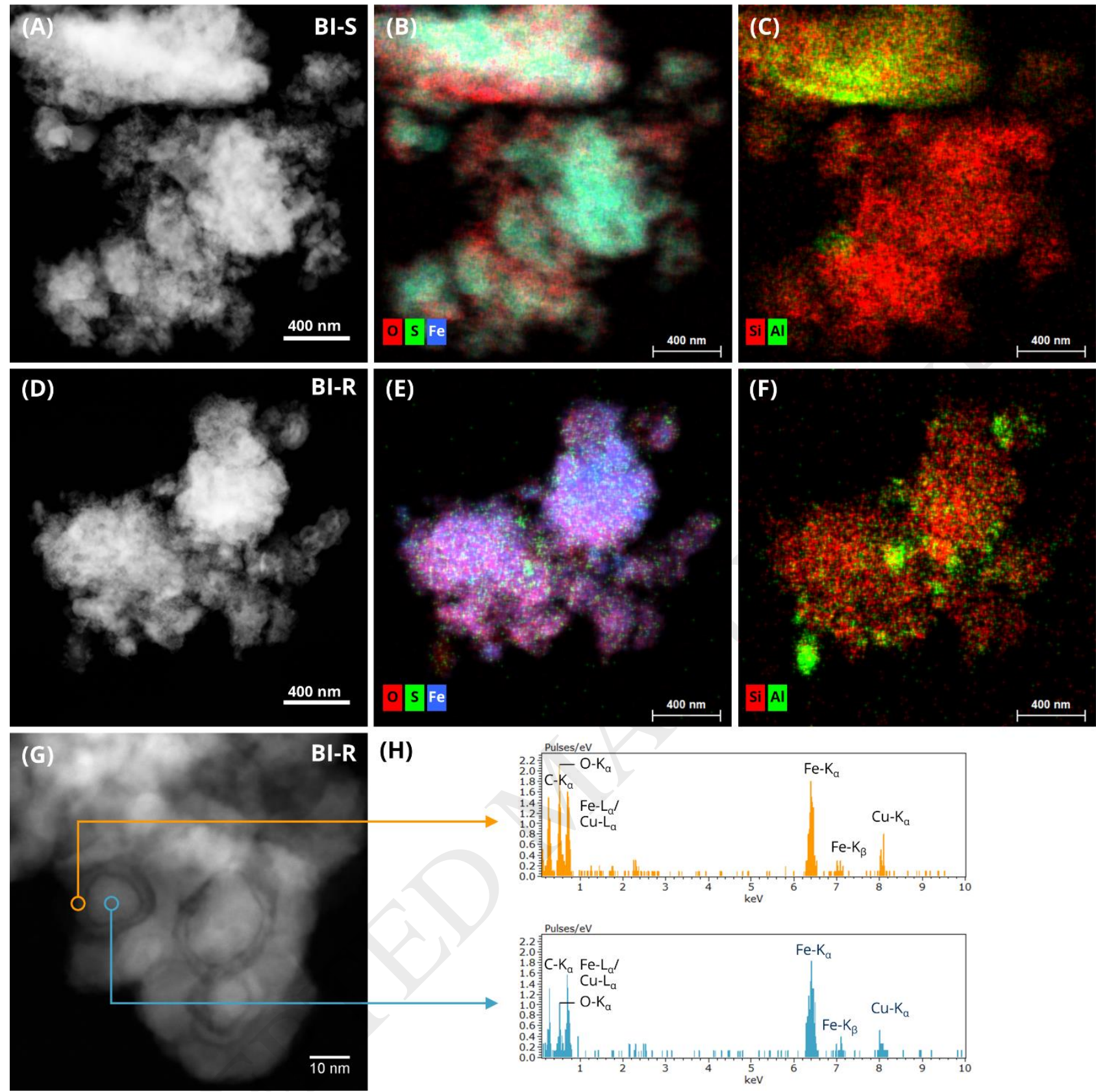

Figure 11 a) HAADF-STEM image of BI-S (from experiment 6) and EDS element distribution of B) oxygen, sulfur and iron, and C) silicium and aluminium. D) HAADF-STEM image of BI-R (from experiment 8) and EDS element distribution of E) oxygen, sulfur and iron, and F) silicium and aluminium. G) High-resolution STEM image of BI-R and H) selected area EDS spectra from regions as indicated in G). 
Table 1 Particle size and surface area

\begin{tabular}{lcccccc}
\hline & CoMo & MgAl & OS & BI & ZA & NiMoZA \\
\hline Particle size $(\mu \mathrm{m})$ & $180-355$ & $180-355$ & $106-212$ & $150-300$ & $180-355$ & $180-355$ \\
Surface area $\left(\mathrm{m}^{2 /} \mathrm{g}\right)$ & ND & 83 & 0.6 & 121 & ND & ND \\
\hline
\end{tabular}


Table 2 Summary of reaction conditions and mass balances for catalytic hydropyrolysis of beech wood using different catalysts.

The data from experiment 1 and 2 has previously been published [38], but are listed here as benchmark experiments.

(Approximately $180 \mathrm{~g} \mathrm{NiMo} / \mathrm{Al}_{2} \mathrm{O}_{3}$ was used in the $\mathrm{HDO}$ reactor)

\begin{tabular}{|c|c|c|c|c|c|c|c|c|c|c|c|}
\hline Test: & 1 & 2 & 3 & 4 & 5 & 6 & 7 & 8 & 9 & 10 & 11 \\
\hline \multicolumn{12}{|l|}{ Test conditions } \\
\hline Catalyst in FB & CoMo & CoMo & MgAl & OS & BI-S & $\mathrm{BI}-\mathrm{S}$ & $\mathrm{BI}-\mathrm{R}$ & BI-R & $\mathrm{ZA}$ & NiMoZA & NiMoZA \\
\hline Catalyst mass (g) & 50.0 & 49.6 & 50.1 & 140.1 & 94.2 & 94.0 & 94.8 & 94.2 & 50.1 & 49.9 & 50.0 \\
\hline $\mathrm{H}_{2} \mathrm{~S}$ fed to $\mathrm{FB}$ & Yes & Yes & Yes & Yes & Yes & Yes & No & No & Yes & Yes & Yes \\
\hline Hydropyrolysis & 451 & 450 & 451 & 450 & 454 & 453 & 450 & 453 & 443 & 453 & 453 \\
\hline \multicolumn{12}{|l|}{ Temp. $\left({ }^{\circ} \mathrm{C}\right)$} \\
\hline HDO Temp. $\left({ }^{\circ} \mathrm{C}\right)$ & 371 & - & 394 & 391 & 389 & - & 394 & - & 370 & 370 & 370 \\
\hline Pressure (bar) & 26 & 26 & 26 & 26 & 26 & 26 & 26 & 26 & 26 & 26 & 26 \\
\hline Feed time (h) & 4.0 & 3.9 & 4.0 & 0.75 & 3.2 & 3.8 & 3.2 & 3.7 & 1.4 & 3.0 & 3.0 \\
\hline $\begin{array}{l}\text { Biomas feeding rate } \\
(\mathrm{g} / \mathrm{h})\end{array}$ & 250 & 174 & 258 & 194 & 302 & 271 & 312 & 272 & 293 & 277 & 277 \\
\hline $\mathrm{H}_{2} \mathrm{~S}$ conc. $(\mathrm{ppm})$ & 460 & 48 & 460 & 460 & 470 & 470 & 470 & - & 471 & 462 & 462 \\
\hline $\mathrm{H}_{2}$ flow (NL/min) & 82 & 87.4 & 82 & 68.7 & 89.2 & 89.2 & 89.2 & 87 & 54.4 & 60 & 60 \\
\hline $\mathrm{N}_{2}$ flow (NL/min) & 5 & 0.62 & 5 & 5 & 5 & 5 & 5 & 5 & 5 & 5 & 5 \\
\hline \multicolumn{12}{|l|}{ Yields (wt. daf \%) } \\
\hline Gas & 31.5 & 27.4 & 27.9 & 27.7 & 25.2 & 19.3 & 24.6 & 17.3 & 28.6 & 29.7 & 30.2 \\
\hline Char and coke $\mathrm{e}^{\mathrm{a}}$ & 11.4 & 12.2 & 18.7 & $\mathrm{Na}$ & 13.5 & 13.1 & 10.5 & 12.7 & 21.1 & 13.1 & 13.0 \\
\hline Aqueous phase & 35.2 & 37.0 & 31.8 & 27.8 & 36.3 & 35.4 & 44.6 & 30.8 & 21.2 & 32.8 & 34.0 \\
\hline Organics & 12.4 & 12.0 & 11.5 & 7.7 & 14.8 & 24.0 & 14.8 & 31.3 & 14.4 & 15.6 & 15.0 \\
\hline $\mathrm{C}_{4+}$ in the gas & 9.1 & 8.4 & 6.4 & 8.2 & 7.9 & 3.0 & 9.9 & 3.01 & 5.9 & 8.2 & 9.1 \\
\hline Organics $+\mathrm{C}_{4+}$ & 21.5 & 20.4 & 17.8 & 15.8 & 22.8 & 27.0 & 24.7 & 34.4 & 20.4 & 23.9 & 24.0 \\
\hline Mass balance & 99.6 & 96.9 & 96.4 & 72.3 & 97.8 & 94.8 & 101.2 & 95.1 & 91.3 & 99.5 & 101.2 \\
\hline \multicolumn{12}{|c|}{ Organic phase composition } \\
\hline Water (wt.\%) & ND & 0.35 & ND & ND & ND & 17 & ND & 5.5 & ND & ND & ND \\
\hline$C(w t . \% d b)$ & $88.0^{\mathrm{b}}$ & $87.7^{b}$ & $87.1^{\mathrm{b}}$ & ND & $88.0^{b}$ & 69.4 & $88.6^{\mathrm{b}}$ & $77.1^{\mathrm{b}}$ & $88.1^{b}$ & $88.8^{b}$ & $88.8^{\mathrm{b}}$ \\
\hline $\mathrm{H}(\mathrm{wt} . \% \mathrm{db})$ & 11.9 & 10.2 & 12.1 & ND & 11.65 & 8.06 & 11.32 & 8.83 & 11.9 & 11.2 & 11.2 \\
\hline \multirow[t]{2}{*}{ O (wt.\% db) } & 0.0030 & 1.8 & 0.008 & 0.001 & 0.020 & $22.1^{\mathrm{b}}$ & 0.0050 & 14.1 & 0.037 & 0.11 & 0.14 \\
\hline & & & 5 & 8 & 5 & & & & & & \\
\hline$S(w t . \% d b)$ & 0.117 & 0.303 & 0.763 & ND & 0.397 & 0.45 & 0.060 & 0.017 & $\mathrm{Na}$ & 0.018 & 0.013 \\
\hline \multicolumn{12}{|c|}{ Organic phase physical properties } \\
\hline $\begin{array}{l}\text { Density at } 40^{\circ} \mathrm{C} \\
(\mathrm{g} / \mathrm{ml})\end{array}$ & 0.8273 & $\begin{array}{c}0.889 \\
0\end{array}$ & $\begin{array}{c}0.825 \\
3\end{array}$ & ND & $\begin{array}{c}0.837 \\
8\end{array}$ & $\begin{array}{c}1.012 \\
3\end{array}$ & 0.8583 & 0.9822 & $\mathrm{Na}$ & 0.8544 & 0.8574 \\
\hline Viscosity at $40^{\circ} \mathrm{C}(\mathrm{cSt})$ & 1.041 & 1.607 & 1.062 & ND & 1.088 & $\mathrm{Na}$ & 1.27 & 4.668 & 1.08 & 1.104 & 1.153 \\
\hline $\begin{array}{l}\text { Energy recovery in } \\
\text { organic phase and } \mathrm{C}_{4+} \\
(\%)\end{array}$ & 51 & 47 & 42 & 34 & 54 & 44 & 58 & 61 & 45 & 53 & 54 \\
\hline \multicolumn{12}{|c|}{ Aqueous phase composition (wt.\%) } \\
\hline Organics & 0.017 & 1.3 & 0.005 & 0.005 & 0.006 & 9.7 & 0.012 & 8.5 & 0.31 & 0.055 & 0.07 \\
\hline \multicolumn{12}{|c|}{ Gas composition (wt.\% daf) } \\
\hline $\mathrm{CO}$ & 9.7 & 11.1 & 9.4 & 8.8 & 7.5 & 5.1 & 6.4 & 4.3 & 9.3 & 7.5 & 7.8 \\
\hline $\mathrm{CO}_{2}$ & 8.0 & 5.7 & 9.5 & 9.9 & 6.5 & 9.9 & 6.7 & 9.9 & 10.8 & 9.0 & 9.1 \\
\hline $\mathrm{C}_{1}-\mathrm{C}_{3}$ & 12.9 & 12.1 & 9.0 & 8.9 & 11.2 & 4.3 & 11.6 & 3.2 & 8.6 & 13.2 & 13.2 \\
\hline $\mathrm{C}_{4+}$ & 8.8 & 8.4 & 6.4 & 8.2 & 7.9 & 3.0 & 9.9 & 3.1 & 5.9 & 8.2 & 9.1 \\
\hline
\end{tabular}


Table 3 Rietveld fitted concentrations and crystallite sizes for fresh BI, BI-S (experiment 6), and BI-R (experiment 8). (X-ray diffraction patterns shown in Figure 10)

\begin{tabular}{lcc}
\hline & Conc. (wt.\%) & $\mathbf{D}(\AA)$ \\
\hline $\mathrm{BI}$ fresh & & \\
$\mathrm{FeCO}_{3}$ (Siderite) & 3.2 & 469 \\
$\alpha-\mathrm{FeO}(\mathrm{OH}$ (Goethite) & 96.3 & 114 \\
$\mathrm{SiO}_{2}$ (Quartz-low) & 0.5 & 4509 \\
\hline $\mathrm{BI}-\mathrm{S}$ & & \\
$\mathrm{FeS}$ (Troilite) & 11 & 632 \\
$\mathrm{Fe}_{0.88} \mathrm{~S}$ (Pyrrhotite) & 74.5 & 202 \\
$\mathrm{FeS}_{2}$ (Pyrite) & 1.5 & 680 \\
\hline $\mathrm{BI}^{\mathrm{R}}$ & & \\
$\mathrm{Fe}$ & 11.1 & 336 \\
$\mathrm{CaCO}_{3}$ & - & - \\
$\mathrm{Fe}_{3} \mathrm{O}_{4}$ (Magnetite) & 71.9 & 123 \\
$\mathrm{Fe}_{2} \mathrm{O}_{3}$ (Hematite) & 9.4 & 405 \\
\hline
\end{tabular}

